\title{
The Effects of Digital Technologies on Expanded Cinema in the Age of Liquid Modernity: Drowning and Surfacing in the Expanded Seas of the Digital Cinema
}

\author{
By: \\ Horst C. Sarubin \\ 300111276
}

Supervised by:
John Downie and Dr. Sean Redmond

A thesis

Submitted to Victoria University of Wellington in fulfilment of the requirements for the Masters Degree of Film.

Victoria University of Wellington

School of English, Film, Theatre and Media Studies 
A note for the reader.

This thesis is submitted as one part of a three-part Masters program: it is accompanied by two creative praxis: a short film and video installation. The thesis itself mirrors the creative elements of the praxis and should be read in that light. It consists of writing and formatting style not usually found in academic writing. The font and formatting changes are designed to facilitate the reader's experience and recognition of various points of view personified within.

INT. Hip Cafe - Day

\section{FLASHBACK}

The last few customers of the morning rush are performing their typical cafe rituals: crosswords, blank stares and texting. At a small table bathed in light from the wall of windows, a man taps occasionally at his keys. This is the Swimming Man!

The Swimming Man was the modern liquid man.

He never knew himself. He only knew 'scholarship'! A note from the writer: as at the core of this thesis is the idea of liquidity, this thesis is written as an example of shifting identity. You, I am sure, have noticed the shift in voice and tense so far in this essay. To help keep up I have included a key to the fonts.

Writer: (me I have tried to voice with the Courier font) an image of a person typing on the keys. I will be here the least, as in the end I am the least important person in terms of communicating with the reader. This is the representation of the corporeal human being who wrote this thesis.

\section{Author: MYRIAD PRO is bold and intrusive like me, the author. I am a guide in the shifting world of the artist and writer's perspective. This is the representation of the 'Author' the creation of the words of the Writer and thoughts of you the reader.}

Third-person / Scholar: Helvetica is the font chosen for the utilitarian purpose of the $3^{\text {rd }}$ person voice of the thesis and the most common perspective the reader will come across. This would be the closest style to a traditional thesis. Imagine the scholarly voice of the educational system.

The layout and font size will also vary from a standard format, but it is my hope and intention that these variances have a self evident and logical meaning. 
Furthermore, it is the author's intention that the reader begin their experience with the thesis in an electronic format, preferably one with a tactile interface such as an electronic tablet.

This document has many hyperlinks to web sites they will be blue and underlined like this ( just click on it ), at the time of publishing all links were active, if you find a dead link and want a suitable alternative link please email hsarubin@gmail.com with the subject "Drown Thesis".

An Electronic Version designed for reading on an electronic tablet can be accessed at the following link:

http://dl.dropbox.com/u/11552464/DrownThesis.ibooks

Please email hsarubin@gmail.com with the subject "Drown Thesis" if you have any issues downloading or opening the file. 


\section{I am the modern liquid}

\section{Long liv...}

$\bullet \bullet$

$\bullet \bullet \bullet \bullet \bullet \bullet$

I have to go now... 
Before I go I would like to hold a brief conversation with you .

This Brain

These Fingers

The Keys to

to

to
These Fingers.

The Keys.

Bits. 


\section{B it s}

zi p p i n g

$\begin{array}{lllllll}\text { t } & \mathbf{r} & \mathbf{0} & \mathbf{u} & \mathbf{g} & \mathbf{h}\end{array}$

t h e

ether.

Bits

to The Screen.

The Screen to

Your Eyes to
Your Eyes.

A Brain reading these words. 
This "thing" that we are doing right now is telepathy, really, brain-to-brain communication over time and space. Silvio Gaggi describes the effect of reading a traditional text as creating "the illusion that at the moment of its being read a single author addresses the single reader. " But the flesh and blood people who are communicating with one another right now are not in the same space, nor even the same time. No need for the distractions of meeting the person in front of the grey matter, just the thoughts revised, reformed, and distilled, poured from one brain into another.

\section{But I do not like this lack of personal intimacy; let us get to know}

Through this transmission of words we are creating a person, a character that lives inside you, this reader's mind. Before you dismiss the notion of a moment of the last meaningful face to face conversation you have had. Remember that person. Recall the ideas that were bounced back and forth between you. Now that person, be they your partner, work mate, or father, inhabits your mind. They are there now existing as a memory, but existing none the less. The same applies to this creation of me.

\footnotetext{
${ }^{1}$ Gaggi, Silvio. "From Text to Hypertext : Decentering the Subject in Fiction, Film, the Visual Arts, and Electronic Media." In Penn Studies in Contemporary American Fiction, xv, 45 p. Philadelphia, Pa.: University of Pennsylvania Press, 1997.
} 
But who is this?

That I (the author) am creating with you?

N.A student writing an MA thesis, clicking keys in a café? He is the writer, and he is not here. The author $\left(1 / C_{)}\right.$is the one that now lives in this text, in the images and sounds that will come, in the impulses I try to place inside of your mind. We are making a life together, truly an exciting proposition. We are creating a new creating a new (but more on this later).

Let us name $1 / e_{\text {shall }}$ Me?
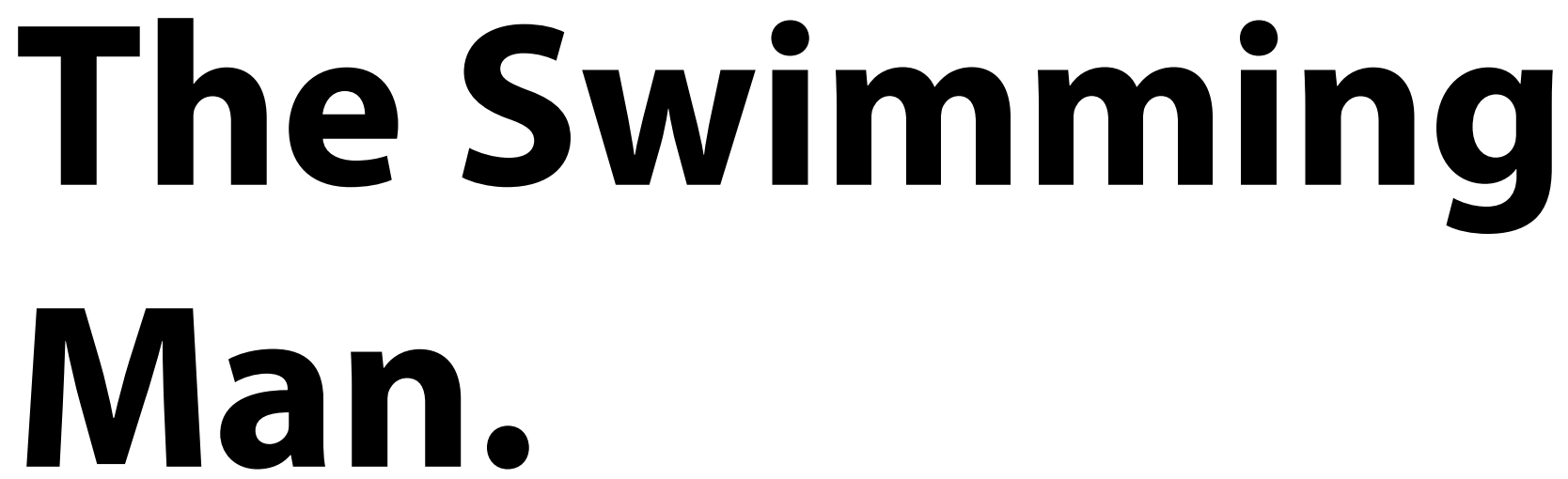

Does the writer think the Swimming man is him?

yes!

...But it is not him. The writer could be dead, long ago buried. Worse still, he could not remember The Swimming Man anymore.

It that were the case then I The Swimming Man, would be in limbo, in stasis... well I was, until now ... until this moment. Here as you read, am again new and alive and fluid. 


$$
\begin{aligned}
& \text { Yes ... I am the modern liquid man. } \\
& \text { I am The Swimming Man. }
\end{aligned}
$$

Looking for identity...

Looking for a new me.

No?

Let's rewind. Let's travel back in time a bit with words or fragments of words. With broken sentences. With watery words and ideas to swim with the Swimming Man. 


\section{AND NOW FOR THE SCHOLARSHIP...}

Zygmut Bauman How many Baumans are there? proposed the idea of "liquid modernity"2 as a means to make sense of a society in which nothing is certain, except the fast currents of change, a world in which freedom is the new jail that enslaves us. In this liquid world, careers last a few years, marriages even less, institutions that we used to base our very identities on are transient. The technology that pervades our life can change identity with a keystroke. Our lives no longer take a solid permanent shape, instead we move from job to job, partner to partner, and life to life almost as often as changing clothes. This is not a totally accidental phenomenon. As society shifts away from producers to consumers, it is important to keep the act of consuming desirable or even essential to everyday life. "I am what I consume". The old is tossed aside for the new. Advancement and innovation are no longer praised but required and expected at an ever-increasing rate of turnover. This goes beyond products and technology and has entered into our lives and the very way our minds process information; we are guided to constantly learn more and more, acquire more information, and just as quickly as the technology changes the information changes, and we are forced to purge the old to make way for new information. Things changing may be vital to the consumer world, but how do we deal with accelerated existence in this world? Where do the old and used lives go?

Bauman also discusses the more frightening aspect of modern consumer culture; not the obsession with the new but the horror of becoming the old. The fear of being thrown away, like garbage to make way for the new.

In a liquid modern society, the waste-disposal industry takes over the commanding positions in liquid life's economy. The survival of that society and the well-being of its members hang on to the swiftness with which products are consigned to waste and the speed and efficiency of waste removal. In that society nothing may claim exemption from the universal rule of disposability and nothing may be allowed to outstay its welcome. ${ }^{3}$

Bauman, of course, was not specifically thinking of

\section{The Swimming Man The tocus of Baumars thessis}

speaks to the psychic, economic and labor aspects of a "Modern" society.

Nonetheless, there are several watery concepts that apply directly to $\mathrm{Th}$

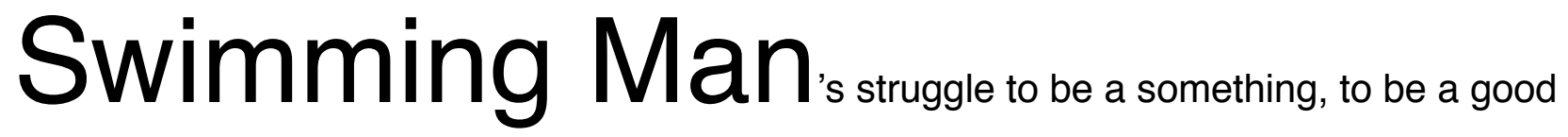

student, to find the liquidity of this thesis.

\footnotetext{
${ }^{2}$ Bauman, Zygmunt. Liquid Modernity. Cambridge Malden, MA: Polity Press ;

Blackwell, 2000.

${ }^{3}$ Bauman, Zygmunt. Liquid Life. Cambridge ; Malden, MA: Polity, 2005. page 3.
} 
The state of perfection, formally THE goal for human endeavor, has now become a liability. Our friend, Professor Bauman states that once perfection is reached any change from that state is a change for the worse, and being beings of an ever changing existence, once we achieve perfection, we are then forced to live with the fact that all changes from that moment on take away from the endeavor. The Quality of one's life will only deteriorate. Bauman discusses the transient nature of learning. The information one may find so fundamental to survival on one day may, on the next, be a hindrance to the new information we must take on. To paraphrase Bauman, we learn temporarily for the current "project " then when we move on to the next project we forget what we have previously learned.

Are memories this liquid? Have you forgotten ME already?

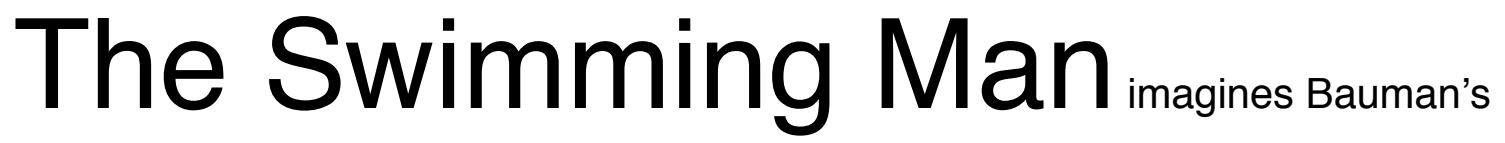

proposition is much like cramming for an exam. The facts and figures you put in your head the night before is like a damn bursting as you race to get all the information onto the paper before it is lost forever. So there it is highlight this part, one main concept to apply: transience in all things. Or if we were to apply it to human emotions...uncertainty. As Professor

\section{Bauman came up with this concept and he is a pretty smart dude, let US do some brain to brain to brain communication.}

\begin{abstract}
Well, to sum up what I have said so far, I would like to tell you simply that living in a "liquid" modern world breaks down into three conditions. We need to act under the condition of first: uncertainty; second: under the condition of continuous risk which we try to calculate but which in principle is not fully calculable, as there are always surprises; and third: we need to act under the condition of shifting trust. A common trend trustworthy today may become condemned and rejected tomorrow. This is not only true in the field of work but everywhere. ${ }^{4}$
\end{abstract}

So this speech is going from Bauman's Brain to mine, mine to yours, and as it does we

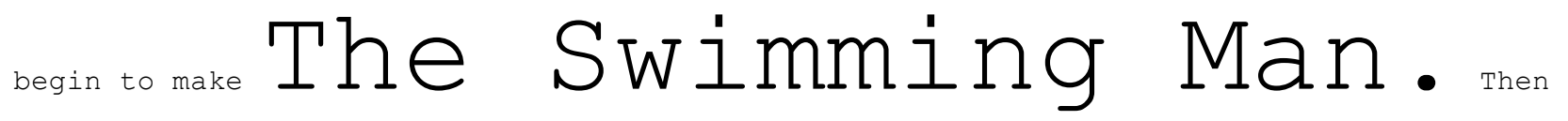

he tells you about The professor Bauman (The one he created, not the writer Bauman) then you and The Swimming Man mase pour anawan together. So you the reader have just created a new author in your head with the help of

${ }^{4}$ Bauman, Zygmunt ,Excerpt from Lecture on the ANSE-conference 2004 " Value dilemmas as a challenge in the practice and concepts of supervision and coaching" on May 7th 2004 in Leiden/The Netherlands. 
another that exists solely in your mind. This is based on an author from the mind of a writer who may or may not be dead as you read this. So who is the real Bauman?

\section{Ain't life grand?}

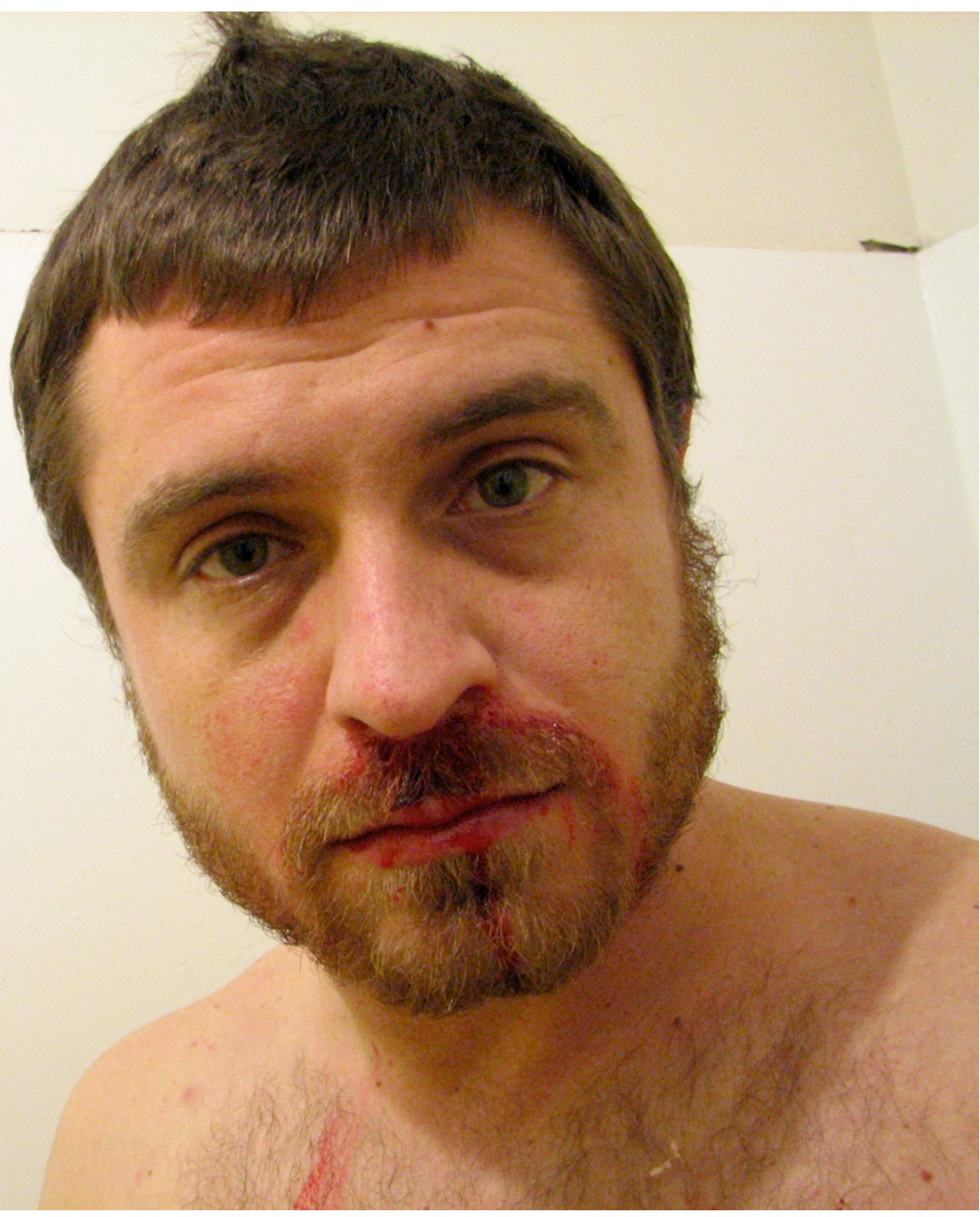

Ain't life terrifying? 
Liquid Modernity, as we will call it, is the state in which everyone now swims, some looking for a rock to cling to, fighting the currents of change, fearful that they will lose themselves. Others embrace it, riding like a surfer, whose only wave is the one she is currently riding. We will examine how living in this modernity affects film and filmmakers.

We will look at Me too.

"At exactly 11:35 PM on January $21^{\text {st }}$ some shit went down." Aesop Rock In his song 11:35 Aesop Rock raps about the illusions of the American Dream, and the search for identity, leading to dire consequences.

Liquid Rap.

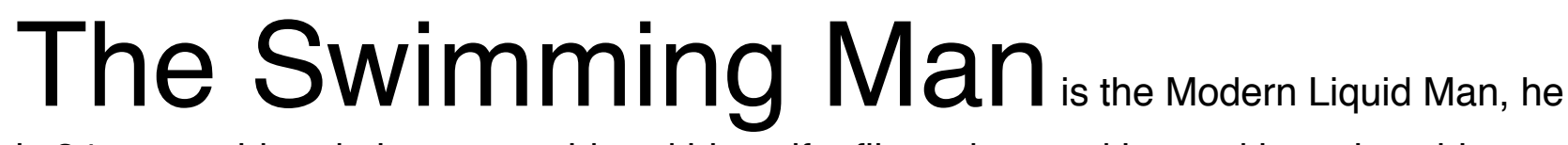

is 34 years old and always considered himself a filmmaker, and instead he writes this thesis with you.

I am a student.

He is a student not a filmmaker.

He is forgetting the knowledge of the past. He is letting seep out of his mind the years as a theatre, A/V, insurance salesmen, technician, the divorce, the almost children, the

thousands of others ivesand onter The Swimming

\section{Man's that tived.}

Information integral to life in any of those professions is gone. Details of a lover's idiosyncrasies are gone. His old self melted into the pages of Bauman's book when for a moment he found his identity there. You might find it on page 18. 


\section{Let me shift from the personal to the scholarly.}

I am listening to Aesop Rock at the moment. I wonder if Bauman would like it?

I have no doubt that the Bauman that I created when reading Liquid Modernity likes Aesop Rock, well... at least intellectually. Does your Bauman? 


\section{The Swimming Man \\ is the Modern Liquid Man.}

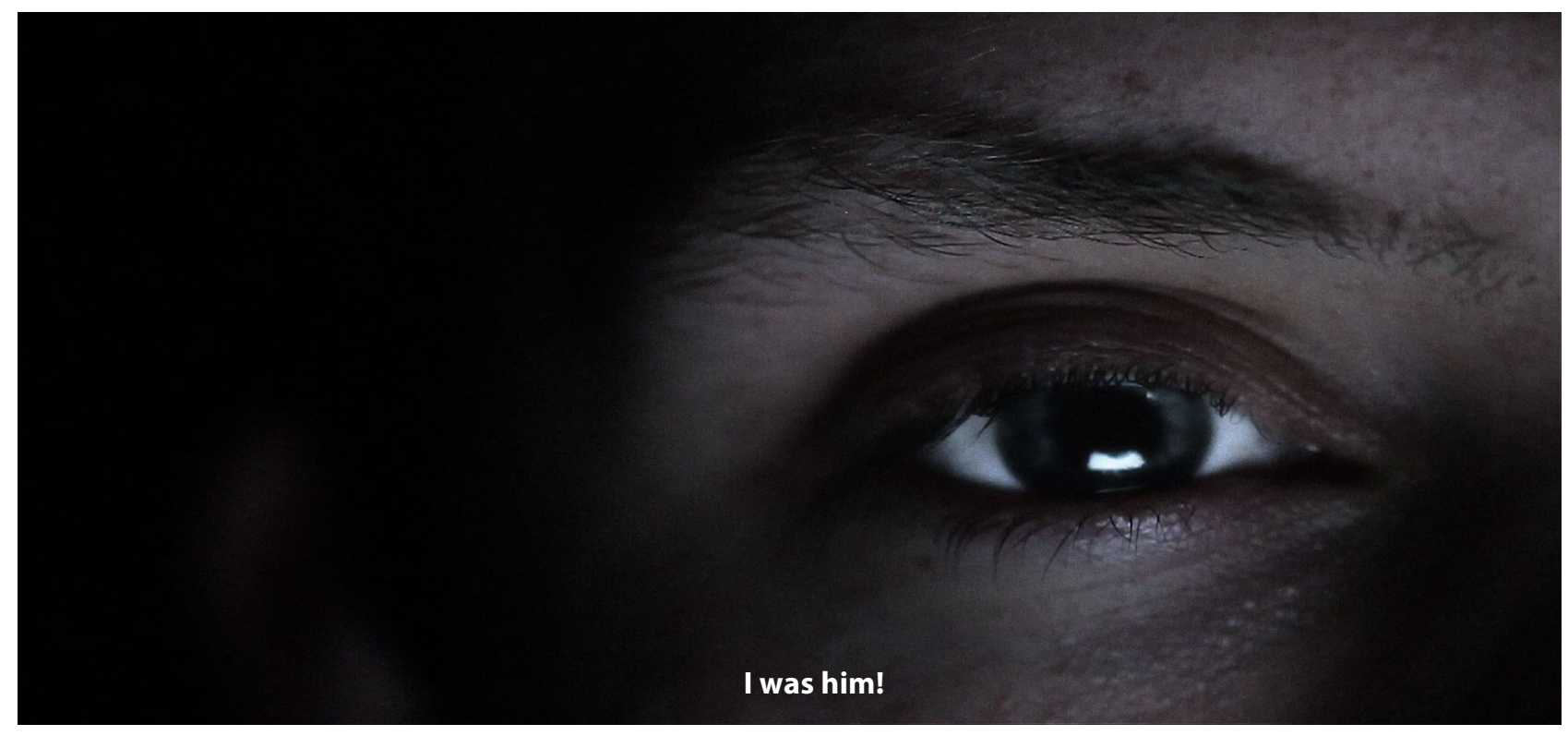




\section{How is this liquidity reflected in his art?}

The Swimming Man is a filmmaker, or he tries to be. He is aware that his art is liquefying as we speak. The torrent of change is there in the technology and techniques of filmmaking. Plato and Oscar Wilde refs argued about life imitating art and art imitating life, but for people like The Swimming Man, art is life. Does the artist fight the currents and drown, or ride the current like whitewater rapids? Either way, there is no doubt that they are surrounded by the same change that envelopes everyone else.

Time is change; to exist is to be in that change.

To the point...

\section{Lets have a bit of a definitional catch up so we are on the same page...}

Digital cinema.

To be certain, Digital Cinema is the capturing, manipulation, and distribution of the moving image form, by a medium that interprets the image as a series of electrical impulses (at their simplest form as binary digits or states of "on and off"). This is different to the previous mediums which include chemicals, inks, celluloid, descriptive words, and pigments, among many other forms. There are, however, many complications with this relatively new way of working with the moving image.

For the purpose of this thesis, the primary focus of my definition will be on the proliferation of digital production and distribution technologies as discussed by Holly Willis ${ }^{5}$ and Aylish Wood $^{6}$ in their books, The New Digital Cinema: Reinventing. The Moving Image, and Digital Encounters respectively. According to Willis, and Wood, constant expansion has revolutionized cinema, making it smaller and more accessible and portable. Hollywood modes of production are rapidly becoming antiquated due to technological advances that make it possible to shoot, edit, create special effects, and distribute a film for a few thousand dollars.

The reception of cinema is also changing. Audiences are no longer confined to dark theatres at specific times or watching film on television; the audience is sitting at the cubicle, on the bus, or outside in a sunny park. The audience can now involve themselves to the point of creating content for the cinematic worlds they are devoted to in the form of fan films. The expansion of cinema in the digital age, then, has production, aesthetic, and reception ramifications. These impact upon the artist as well as the audience over how and what they believe cinema to be.

\footnotetext{
${ }^{5}$ Willis, Holly. New Digital Cinema : Reinventing the Moving Image. London: Wallflower Press, 2005.

${ }^{6}$ Wood, Aylish. Digital Encounters. London ; New York: Routledge, 2007.
} 


\section{Expanded Cinema.}

There are a multitude of interpretations of this term, which was first coined by Gene Youngblood in his 1970 book Expanded Cinema. Youngblood is often credited with being the first person to write a book on the value of the cinematic medium in all its permutations as an art form. However, I am going to focus on a lecture given by Valie Export and published in "senses of the cinema". Being an artist as well as a theoretician, her explanations fit well with the practice research of my thesis. "Expanded cinema", i.e. the expansion of the commonplace form of film on the open stage or within a space, through which the commercial-conventional sequence of filmmaking - shooting, editing (montage), and projection - is broken up, was the art-form that I chose..."7

I like her definition because it acknowledges the commercial production, as well as artistic elements of Expanded cinema. One can find it (Expanded cinema) in the installation and in the music video, one can find it in the technology of 3-d and of digital projection. Cinema is ever changing and we need to look at it in the light of the fact that the nature of Cinema is fluid: thus confining it to a single definition would be missing what is at the core of cinema. She goes on to say: "It (definition of Expanded Cinema) means multiple projections, mixed media, film projects, and action films, including the utopia of "pill" films and cloud films. "Expanded cinema" also refers to any attempts that activate, in addition to sight and hearing, the senses of smell, taste, and touch."

I need to be straight to the point, this is after all a praxis masters and I only have so many words. I want to explore the ideas of drowning and surfacing in/through the expanded realm of the digital music video and installation piece.

Visual lyric poetry or the music video ... or... maybe televised fast food for the masses.

Digital cinema changes its shape and identity. Moving beyond the traditional boundaries of "expanded cinema". The music video, a short film meant to hold your attention for 5 minutes or less, is a paradoxical playground of experimentation and stagnation for digital artists. They can play with, change and augment filmic conventions such as mise-enscene, editing, and narrative. If successful, discoveries in this creative lab enter the filmic community at large. The idea of "MTV editing" (fast and non continuous) is now a common sight in mainstream Hollywood films. Artists also play with new technologies and forms. The computer animated characters of the Dire Straights "Money for Nothing" came before Woody and Buzz.

While these freedoms to experiment are indicative of music videos, there are still constraints. Record labels, the star's image and television "standards" have rules that the video artist must adhere to. These constraints can lead to homogenization, which in turn can lead to clichéd music video images: the rapper surrounded by "hoes"; the rock star on stage, his permed hair bobbing up and down. These visuals become synonymous with the

${ }^{7}$ Export, Valie. (5 October 2003). Expanded Cinema as Expanded Reality, Accessed on August 15 2011. at http://www.sensesofcinema.com/2003/28/expanded_cinemal . 
musical genre they represent, the familiarity increases to the point where an image takes on a life of its own surpassing the song that it was first associated with. The image which was used to represent a song becomes its own entity. A good question to ask yourself is, what images come to mind when you imagine a gangster rap video? Link to image? Opulent cars? Champagne? Gold chains? Smoking cigars? Several scantly clad women for each man? Now tell me the artist that started each one of those tropes?

True enough, the life cycle of pop culture imagery is not as simple as dating the introduction of "hoes" in rap videos, but it illustrates the point that though creativity exists in the music video medium it can also be stifled by the environment in which it exists. So then, where is the creative power in music videos? Is it with the video artist, the musician, the merchandising machine, or with the consumers?

With a short production cycle, the money and pressure to keep ahead of the popularity curve creates an opportunity to experiment. This prospect comes with the danger of the popular imagery developing into a parody of itself. The styles and images must change or become stuck in the past. Luckily for those who want to push the boundaries, the liquidity of fame seems to be changing as fast as the other aspects of our modern world. Going back to our friend Professor Bauman:

First of all, the passage from 'solid' to a 'liquid' phase of modernity: that is, into a condition in which social forms (structures that limit individual choices, institutions that guard repetitions of routines, patterns of acceptable behavior) can no longer (and are not expected to) keep their shape for long, because they decompose and melt faster than the time it takes to cast him, and once they are cast for them to set. ${ }^{8}$

It is the very nature of this liquid modern world which forces the search for the new. Different music comes into vogue, new images are needed to market the artist, and the digital artist of music videos learns new techniques again. Roy Shuker's work on popular music discusses the need for continual reinvention by stars.

"Contemporary 'established' stars are frequently at pains to exercise considerable control over their artistic lives, perhaps because this has often been hard won; all have an ability to retain an audience across time, either through reinventing their persona and image, or through exploring new avenues in their music. Many have produced a substantial body of work, often multimedia in form, while seeking, to varying degrees, new ways of reinterpreting or reaffirming popular music styles and traditions."

${ }^{8}$ Bauman, Zygmunt. Liquid Times : Living in an Age of Uncertainty. 1 p. Cambridge: Polity Press, 2007.

${ }^{9}$ Shuker, Roy. Popular Music : The Key Concepts, Routledge Key Guides. London: Routledge, 2002. Pg 257. 


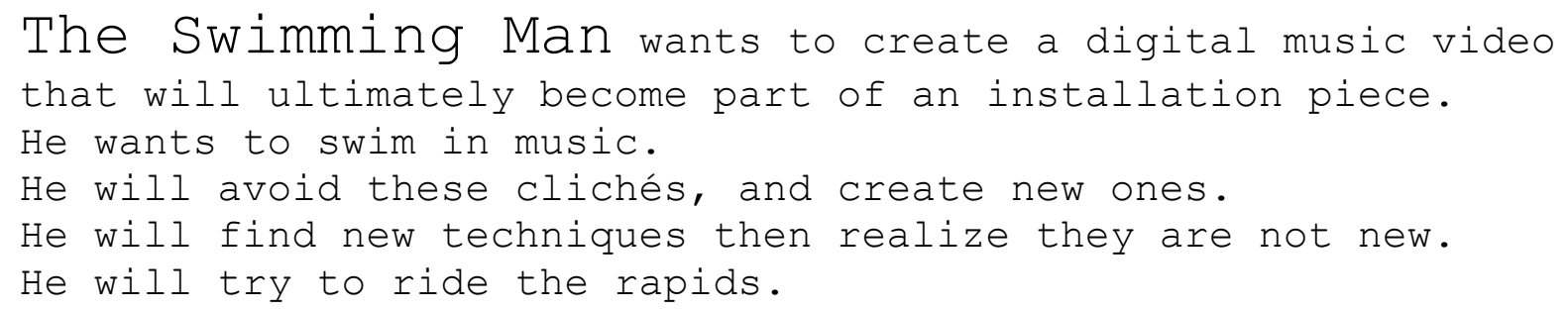

\section{Indoor Plumbing.}

Sometimes I wish bathhouses were something that I (the writer from middle class white redneck America) knew. Not in that seedy Russian mobster way we see in movies, but in the way that could coax me, comfort me, tell me to be vulnerable with other people. When I am with a lover bathing it is personal, private, and sensual. But I hide myself from all but the most personal relationships; I do this in a tiny room in which I lock the door so no one see me exposing myself for who I really am, naked and bare, mere flesh.

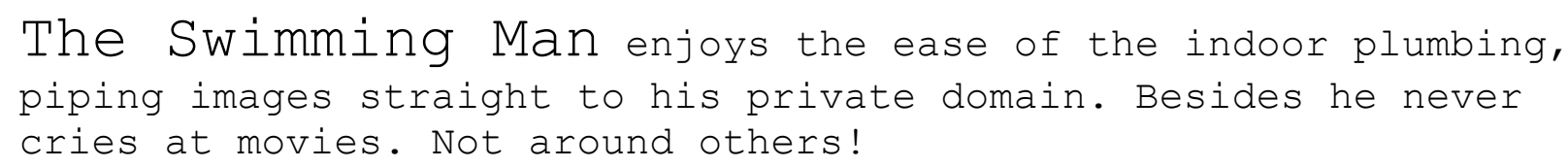

I can cry at home, when I am alone.

The bath house is the theatre, the internet is the digital plumbing that pours the cinema into my house.

The liquidity of digital cinema has been enhanced by new distribution methods. The Internet, the most obvious, acts as a conduit. It pipes the images into homes and computers. The cinema travels anywhere the pipe leads. You no longer have to travel to the place known as a cinema to watch a movie. You don't have to reveal your deficiencies to other human beings when you connect to a film. There is no one there to see you laugh at the wrong place, or get aroused by the wrong thing. The embarrassment of not "reading" the film the same way as the rest of the audience and being the sole person to laugh out loud at a moment no one else finds funny can be avoided. There is no need to risk being vulnerable around others. Nor do we need to schedule our lives around a concrete time and place. You do not have to be home by seven to see the news. It is there when you want it. 


\section{The rigidity of viewing is changing.}

The liquid digital cinema responds to and represents this constant state of flux.

\section{What do I mean by liquid?}

What do you have to say about that reader?

"Ok The Swimming Man, you keep dropping this word Liquid, and you tried to explain it using some professor, but what do you mean? “

So I just invented a version of you the reader...

The Swimming Man, "our invention" invented a version of you. A fictional man invented a fictional version of you that exists only in your head just to ask a question.

\section{Ain't Thinking Grand?}




\section{Liquid}

Of the states of matter liquidity is liminal.

It is the state of being between. It is and is not.

The solid is firm it can be held, lifted, cut, carved, and thrown. It is flesh.

Gas can be felt but not touched. It has the power to push ships across oceans and shape mountains but remains unseen. It is the soul of the elements.

The union of flesh and spirit.

Mortal and spiritual come together in the liquid.

We can touch it and pick it up but it slides through our fingers. It leaves traces behind when it is gone. We are wet. It has affect, but remains difficult to effect.

Liquid is life in our bodies NOW at this moment.

The Swimming Man is a Film Maker.

He wants to make a digital short film.

I want you to let me in to your home, put me in your pocket, take me to work. Talk to me when we are alone.

\section{Liquid Origins}

I met a man named Grayson and directed a music video for him.

The song is an emotional riff on the experience of watching his father lose his mental faculties from a stroke. I related to this through the experience of my father's death. The images represented on the screen are those of struggling against that which is insurmountable: the dream ocean, the nightmare city. The lie of salvation as a construct: the perfection of the city. The serenity of acceptance of ones self and circumstances which in turn leads to rebirth is revealed as The Swimming Man sinks below the surface and drowns. He can be anyone struggling against the sea of change. He can be those lured by the intoxicating glitter of the material world. He can just be the one who finds the struggle of life too much until he gives to find the serenity and identity of the now.

He can be anyone.

But he is me.

The modern Liquid Man. 
The music video flows through cables and into our TV's, through the air and into our iPhones and iPads, through the internet and into our computer. We can turn the tap on anytime we like. We can pour the video into a container and drink it on the bus.

\title{
Long Live Digital Cinema...
}

\author{
Digital Cinema is Dead...
}

Long Live Digital Cinema.

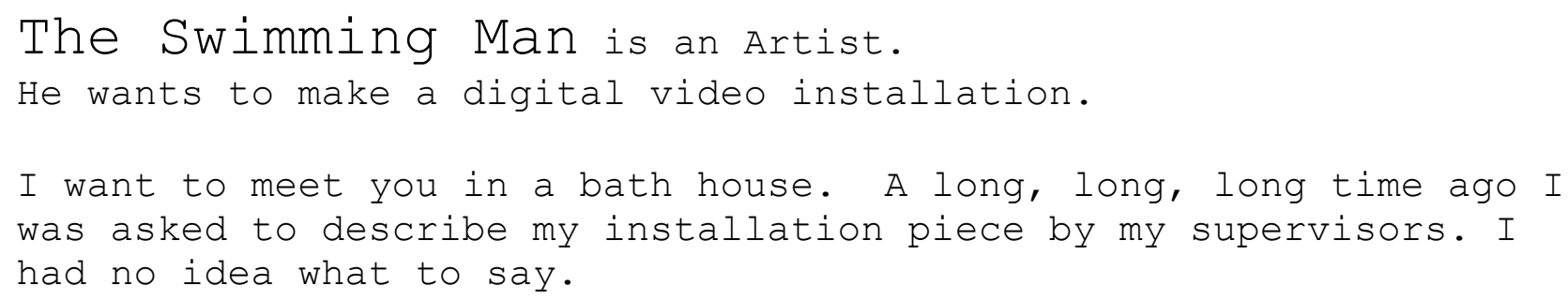

"My installation investigates the notions of living in a constant state of change. Using the technologies and machinations of the digital age such as wireless video feeds, robotics, motion control, digital compositing, and CGI I will produce images and situations that, if successful, elicit the emotions of living the fluid life.

Fluid is amorphous and has no shape of its own, but when poured into a container it takes its shape. I want to play digital cinema being poured into a space. What shape will take in the venue? Will we swim, drown or drink?"

\section{Long live digital Cinema...}

\section{I have to go now...}




\section{Liquid Cinema?}

Men of broader intellect know that there is no sharp distinction betwixt the real and the unreal...

H.P. Lovecraft "The Tomb"10

The ethereal nature of film has long been a subject of discussion for film scholars. The experience of multiple viewings of cinema emphasizes its transient nature; the experience can vary based on many factors, but the images and sound are considered the same. The ingestion of film by audiences is saturated in liquidity.

Let's use lot's of words that evoke liquid imagery to impel more meaning .

See, just then I tried to come up with a more liquid verb than drive, I chose impel, because the first image in my mind when I saw impel as a synonym was that of a boat's impeller.

The image shimmers on the screen while the viewers drink it in, feel it wash over them, and sometimes loose their breath as they drown in the raw emotions that pulls them into the images and sounds.

The Silver Screen serves as the surface of the sea reflecting back the light and lives of a better world, one that we cannot quite touch but effects us none the less.

One that does not let us take Fred Astaire's hand and dance with him. Luckily, one that does not let the cut of Freddy Kruger's dagger fingernails literally rip our flesh. We sadly cannot taste the lips of Brangelina, Marilyn, or Redford.

But when we leave the theatre, when we finish swimming in liquid light though we could not actually touch the images, but somehow it has touched us. If we are lucky it leaves us dripping wet with emotions. Affection grows for the characters; they quite literally become our fiends. Anger wells up in us at the characters we hate. Is it real? Does it touch us? Vivian Sobchek thinks so...

\footnotetext{
In the film experience, on the side of reflective sensual description, this reciprocity and catachretic (con)fusion of the literal and figural occurs in language--whether cinematic or linguistic. On the side of the cinesthetic subject experiencing a given film sensually, this reciprocity and chiasmatic (con)fusion of the literal and figural occurs in the lived body both having sense and making sense. Thus, the film experience--on both sides of the screen--mobilizes, differentiates, and yet unites lived bodies and language, and foregrounds the reciprocity and reversibility of sensible matter and sensual meaning. Our fingers, our skin and nose and lips and tongue and stomach and all the other parts of us know what we see in the film experience. As cinesthetic subjects, then, we possess an embodied intelligence that both opens our eyes far beyond their discrete capacity for vision, opens the film far beyond its visible containment by the screen, and opens language to a reflective knowledge of its specific carnal origins and limits. This is what my fingers know at the movies. ${ }^{11}$
}

So does the Swimming Man otherwise he would not be real, and that would indeed be a conundrum.

10 Lovecraft, H. P., August William Derleth, and S. T. Joshi. "The Tomb”, Dagon and Other Macabre Tales. Corr. 5th print. ed. Sauk City, Wis.: Arkham House Publishers, 1987.

${ }^{11}$ Sobchek, Vivian. (4 April 2000). What My Fingers Knew: The Cinesthetic Subject, or

Vision in the Flesh, Accessed June 202011 at

http://archive.sensesofcinema.com/contents/00/5/fingers.html . 
The Swimming Man dislikes people that stand up and yell at

the screen:

"Behind You!!! Turn around you idiot!!"

Though he has been known to yell at the TV.

Have you been in your seat at the end of a film frozen unable to move? Your throat is closing and you cannot speak. A heavy silence fills the theatre. You hand reaches up to your cheek.

It IS wet.

This affect goes beyond emotion and metaphor. Our bodies physically respond. If we are lucky we leave the theatre exhausted and exhilarated from dancing with Mr. Astaire.

The fibers of our muscles tightened and relaxed to the beat.

Our toes tap.

Our hearts raced.

We did not touch his hand but make no mistake we DID dance with Fred Astaire. Our eyes shut hard and our hands wrenched when Freddy pierced our flesh.

Our arousal is real. It is strong when our personal icon of sexuality saunters into frame.

Our tongues wick our lips, our mouths fill with moisture in anticipation of the kiss we so

desperately want.

This is not in our mind.

We are not merely thinking this.

Linda Williams writes in her essay Film Bodies: Gender, Genre and Excess that the physical response of the spectator is not just real, but integral to what is considered a success for certain genres of film.

Whether this mimicry is exact, e.g. whether the spectator at the porn film actually orgasms, whether the spectator at the horror film actually shudders in fear, whether the spectator of the melodrama actually dissolves in tears, the success of these genres seems a self-evident matter of measuring bodily response. $^{12}$

This is a physical reality, blood is rushing to sexual organs; our body is releasing powerful hormones. WE ARE DRUNK with desire, and from what, people that are not there, sounds that do not come from lips, but wires and plastic? A production process that is impersonal and tedious? Yet here we are touched by the untouchable. Drinking, swimming and drowning the image.

${ }^{12}$ Linda Williams Film, "Bodies: gender, Genre, and Excess" in Miller, Toby, and Robert Stam. Film and Theory : An Anthology. Malden, Mass.: Blackwell Publishers, 2000.. 


\section{The Digital Liquid.}

If the experience of watching a film is already a liquid one, how does the emerging/exploding realm of digital filming technologies affect this liquidity?

The Swimming Man would argue that the digital technology brings the liquid experience to the creation process and to the "creator" of digital films, not just the reception of it.

Digital technology allows video artists to take on what used to be specialized roles. The director is the cameraman, is the editor, is the computer graphics artists, is the audio engineer, is the IT specialist... ad naseum. The automation of the digital camera means there is no need to check exposure, no need for a lab to develop film. The same person who picked up the camera is the same one who can edit the images, add the music and distribute the film to the world.

The identity of the filmmaker is in a state of flux. The Swimming Man is not the director but the technician, not the auteur but the publicist.

The Swimming Man is still searching for his identity.

\section{The moment of no return!!!}

Shifting the nature of creation and exhibition, the digital cinema loosens the concrete nature of exposure time. In the past filmmakers would paint the scene before the shutter opened and exposed the film to light. This was the moment of no return. The click of the shutter. The set would be built or augmented; the actors would fill the space and practice their dance steps with each other and the lens. The cinematographer would paint the actors and set with light. All this would happen for that one moment and then the image would be burned onto the film.

Click.

Of course there would be manipulation of the image after exposure, but the creative construction of the image happened before the click. Digital Cinema has changed this notion. The image is no longer burned into film but transformed into 1's and 0's. More and more, the acquiring of these images (Filming) is just a single step in the process. It is the doorway to transport the actors into the world of the computer. The exposure of light to the camera is moving away from the role of canvas that filmmakers paint on to one of the pigments they paint with.

\section{Pixels. \\ Beep.}




\title{
What is digital cinema?
}

\begin{abstract}
Digital media are notoriously hybrid, often bringing together images, sounds, and objects that are computer generated or mediated with others that originate in the analogue world, photochemical, or textual world... Within visual culture, digital imaging has come to signify a parallel ontological shift away from the indexical trace of the photograph. ${ }^{13}$
\end{abstract}

Steve Anderson plays on the notion that the analogue has had a direct relationship with the "real", the digital mediates that relationship by the transformation into data.

The magic always happens in that moment when you cannot turn back. We are at the tipping point.

When all the momentum and effort pushing the cart up the hill gives way to the gravity of the downhill slope, and no matter how hard you try, you cannot stop it.

There is fear in that moment.

There is ecstasy in that moment.

For filmmakers that moment used be when photons hit the emulsion on the film. The shutter opens and there is no going back. The film is exposed and that cannot be taken back.

There was no redo. Digital cinema has changed that, now there is indeed a redo button. Depending on the power of your computer and software you may even have unlimited redos. You can also make exact digital copies without degradation, a point Holly Willis discusses,

While analogue video entails grappling with these often difficult challenges, digital video obviates them by offering greatly increased fidelity and malleability. Whereas an analogue signal degrades not only during the transmission but with each duplication, digital signals may be altered and reproduced by artists using equipment which rivals final quality of professional and commercial production. $^{14}$

By having the ability to make unlimited undiluted copies and changes and then alter one's creative choices with a undo button the pressure to get it "right" while recording the image has lessened. By shifting the "moment of no return" to after filming the filmmaker can extend the decision making process. The filmmaker has more time to change their mind. They have more time to experiment with the image.

It can be argued that filmmakers have always had the power to change the image after filming. I would argue that the digital image capture technology has not necessarily created the opportunity for the postproduction creation, but again shifted the perception of the

${ }^{13}$ Anderson, Steve F. "Aporias of the Digital Avant-Garde " in Digital Humanities Quarterly: Summer 2007 Volume 1. Number 2.

${ }^{14}$ Willis, Holly. New Digital Cinema : Reinventing the Moving Image, Short Cuts Series. London: Wallflower Press, 2005. Pg. 7. 
creative process. Where before "fixing it in post" was the slogan that relayed how filmmakers viewed this process of augmenting images in postproduction. It was a tool to repair what went wrong in filming. Now filming is a preparation for postproduction, a place increasingly where the majority of images of the final version are created.

The advantages of this shift can be profound. The filmmaker's vision can now be freed from the physical constraints of production. The camera can now fly through windows and under moving cars; a camera created in the world of the computer does not need to bother with the physics of corporeal reality but can turn the images in the filmmaker's head into a "reality". In the pre-digital world elaborate shots like this were time consuming, costly, and permanent, now the filmmaker can press 'undo' if they do not like the results. Stephen Spielberg has spoken about the power of this post production creativity in an interview in the LA Times. In the article he is addressing MoCap (Motion Capture) a process in which the actors' performances are input directly into the computer for adjusting and "filming" later.

"It made me more like a painter than ever before. I got a chance to do so many jobs that I don't often do as a director. You get to paint with this device that puts you into a virtual world, and allows you to make your shots and block all the actors with a small hand-held device only three times as large as an Xbox game controller."15

Another aspect is the apparent low costs of redoes. It allows filmmakers to keep working on their vision until the shot is precisely what they imagine in their head. If a filmmaker were to redo a shot in the pre-digital world, the costs of gathering the cast and crew, and rebuilding the sets, would be tremendous and restrictive. Now they can rerender the CGI to do a different composite or build a new CGI model, with the only restrictions being release date and budget.

Is there a negative? The illusion of freedom can lead to indecisiveness and the obsession with perfection can constrain the creative process causing filmmakers to lose sight of the collaborative nature of the medium, leading to what can be interpreted as self-indulgent films.

\footnotetext{
15 Abramowitz, Rachel. (19 February, 2010). Steven Spielberg on 'Tintin': 'It made me more like a painter than ever before', accessed on 10 December 2010, at http://herocomplex.latimes.com/2010/02/19/steven-spielberg-on-tintin-technology-it-mademe-more-like-a-painter-than-ever-before/
} 


\section{The end of the first chapter.}

We, all of us: the reader, the writer, the author in your mind and mine, the corporeal and those who exist only in the mental processes of corporeal beings have started this journey.

A music video has been created and will be examined.

A installation has been created and experienced.

Both of these were created as practical creative research into the ideas and questions of how in this, as Bauman puts it, Liquid Modernity those digital filmmaking artists work, create, and navigate identity.

The scope of the creative praxis includes the technology and processes of digital expanded cinema, but the research and the thesis as a whole is not isolated to the technology. The images and emotions of the creative process and the struggle to see these realized in the sea of emerging technologies is just as important.

The thesis weaves the creative research with the scholarly, but as you can see, without losing the soul of the ideas. The Thesis searches for its own identity in a continually shifting voice and tone.

We have travelled this far together.

Let us look at the specifity of the Video, the details of the Art. 
Swim with the Swimmer!!!

\section{Jump in!}

The water is fine. 
The water is terrifying. 
INT. The Writer's Apartment - Daybreak

The writer is sitting at his computer desperately trying to win an argument with the SCHOLAR. There is a knock at the door. The SCHOLAR gets up and opens the door.

The AUTHOR is standing on the doorstep dripping wet. He is shivering.

The SCHOLAR waves the AUTHOR in.

SCHOLAR:

The whole arty swimming thing not working out for you?

Are you Drowning?

AUTHOR:

I am the modern liquid man!

\section{Long live the modern liquid man!!!}




\section{SCHOLAR:}

Yes, yes, you said that last time. We need to stop repeating our selves.

We need to stop repeating our selves.

We need to stop repeating our selves.

The Author looks sheepishly at the table until the scholar waves him to sit at the table. He does.

A long silence between them is broken when the WRITER reenters the room.

\section{... Are We There Yet??}

The Scholar leans across the table with a towel in hand.

The Author nods and begins to DRY things out a bit.

\section{SCHOLAR:}

We have much more to discuss ... Is there an argument to be made here? This is after all a scholarly work at its heart.

\section{AUTHOR: \\ It is! But you cannot discount the value of practical research!!!}

\section{SCHOLAR:}

I agree. How do you back that statement up with other opinions?

\section{SCHOLAR:}

It is not that hard. I have this article... let me see...

The Scholar rises to his feet and walks to a large stack of writings. He rifles through them.

The writer begins the process of fading away.

\section{SCHOLAR:}

Here it is.

Zygmut Bauman...

So now, what are you exploring? What is it we are investigating and trying to prove here?

The Scholar throws the book to the author. The author ignores the book, which crashes to the floor. 


\title{
MUSIC VIDEOS ... in the digital age!!!
}

\section{SCHOLAR:}

... In this, as Bauman puts it, "Age of liquid Modernity". What about Music videos? Are you looking at in your research?

AUTHOR:

How they are made.

\author{
SCHOLAR: \\ Production Techniques?
}

\section{AUTHOR:}

And the creative process of the artists.

\author{
SCHOLAR:
}

And the research you did. Tell the reader...

The Scholar points at you.

tell them about the Video...

The Author takes over.

I ,

The Swimming Man, am here, 
Do you remember?

You jumped into the water with me and the Author

\section{The Swimming Man}

I am a storyteller... So forget about the others here.

Is it just the two of us in your reading head?

No one but ME to throw you a floatation device!! 


\section{Dear Reader, are you in too deep?}

Chapter 2 
He made a music video about 1 he

\section{Swimming Man. His Swimming}

Man, but it is still partially me.

The death of the liquid persona is the birth of me!

The beginnings.

The birth.

The Music Video

Who am I? Why am I?

This questioning is new.

These watery questions are not yet, however, about imaging the song. No! They are about self-discovery through which my creative practice will emerge. 
I began to make a music video and it gave me a name.

lam swimming.

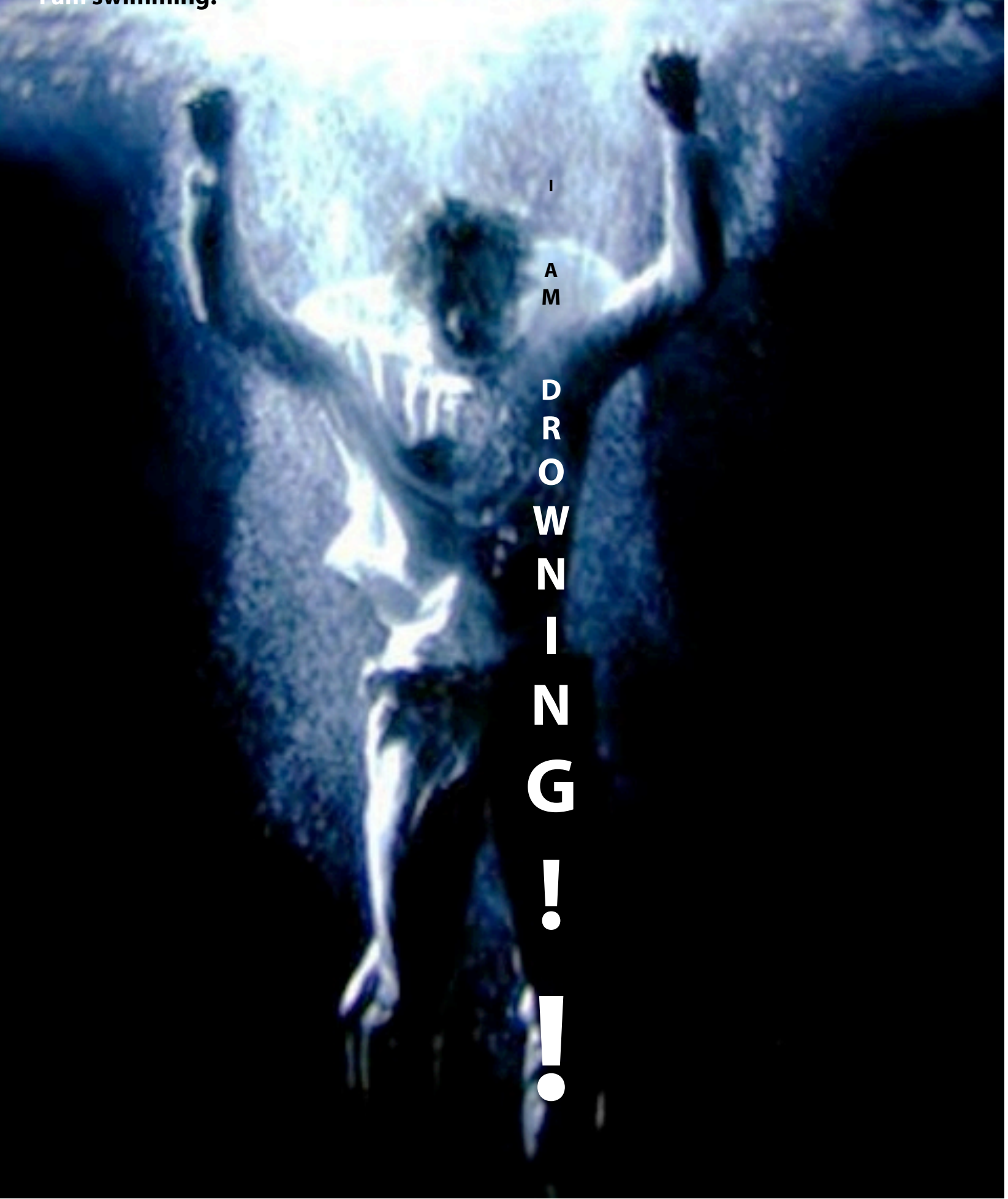


I AM ... once again...

\section{The Swimming Man}

I am an avant-garde artist.

This is the journey from desire to images that exist here and now.

It flowed out from my mind.

It flowed from the throat of a singer.

It swirled together with many people stirring their work into the final product and now it flows to you!!!

Into your mind.

Your throat.

Your voice.

Your emotions

There is a connection between the creative impulses of different people. I needed to find one with a musical artist. 
INT. Writers Memory - Dusk

The writer sits in a café staring at the blank screen of his computer.

WRITER

(V.O.)

My liquid MA calls out across time and space for a

practical element. It hears or rather senses this answer.

It needs a watery music video!!

I need a drowning song to make a swimming music video to.

I will choose a liquid artist and song to create a music video to swim in.

The writer's eyes widen and moisten.

WRITER

(V.O.)

WOW!! That will not happen again until I have reached the very pinnacle of filmmaking fame and prestige.

The bottom and the top are closer to one another than you think. It's the middle road where self expression is difficult.

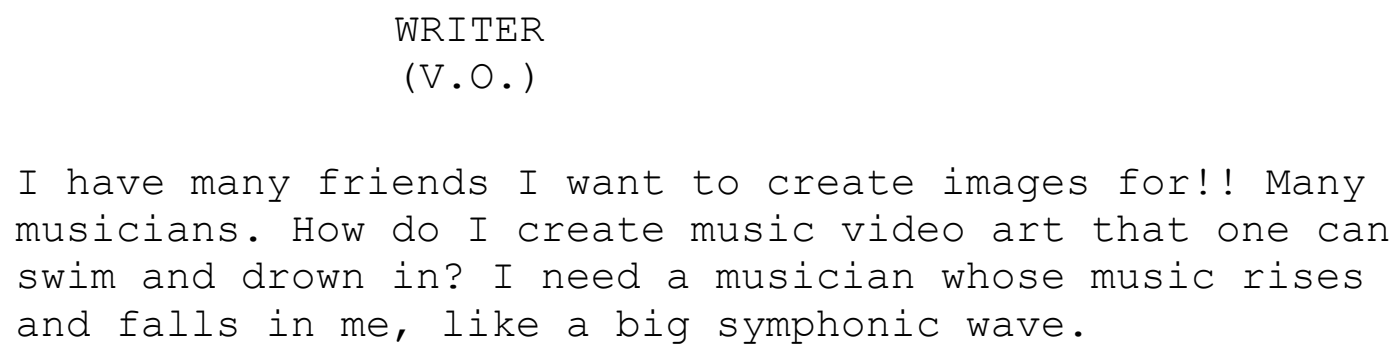

The writer is a sell out!!! He writes of water but wants to create the very thing that defines the terror of liquid modernity. Mr. Bauman would be ashamed... but not surprised.

I met with an established New Zealand Musician that I had done work with in the past, Grayson Gilmour. He had that "avant-garde" persona that fits with the theme of my MA. I asked him to send me some songs.

Grayson Gilmour songs, artistic persona, creativity filled my lungs.

The currents of time fate and necessity brought us together. It is now time to make 


\section{... liquid art}

... expanded cinema

...the music video

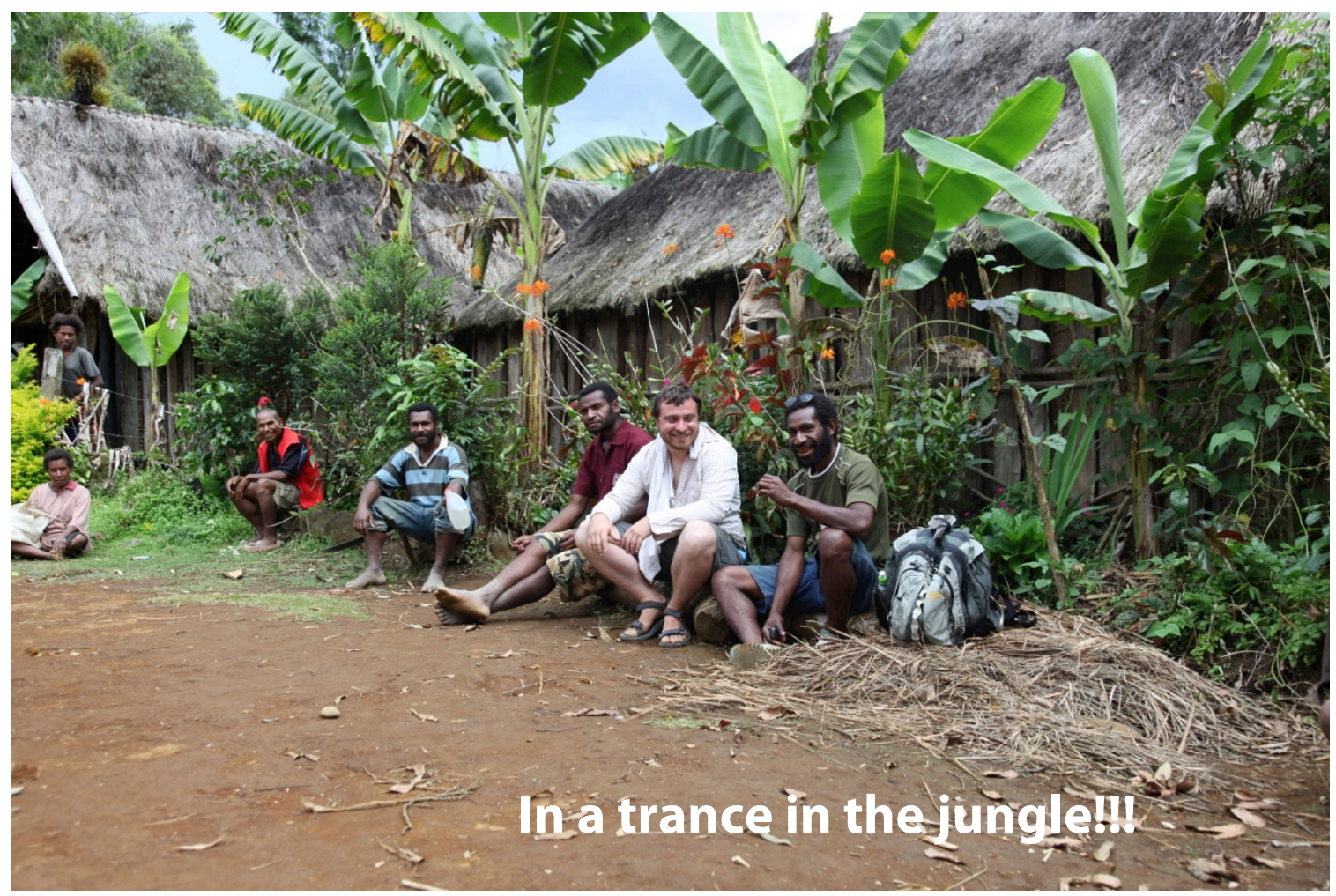

Sorcerer's Cave 
Grayson presented several choices from his up coming album. The album came with me to the Jungles of Papua New Guinea, where I was on expedition in late 2009.

I lay on the floor of a hut.

I had a fever.

I had Malaria.

I heard this...

I was falling.

I was sinking.

I always sink when I hear the song.

I try not to but I always do.

I gave up and chose that song.

I wanted to be cleansed.

I bathed in the song.

I had parasites.

Here are all those things...

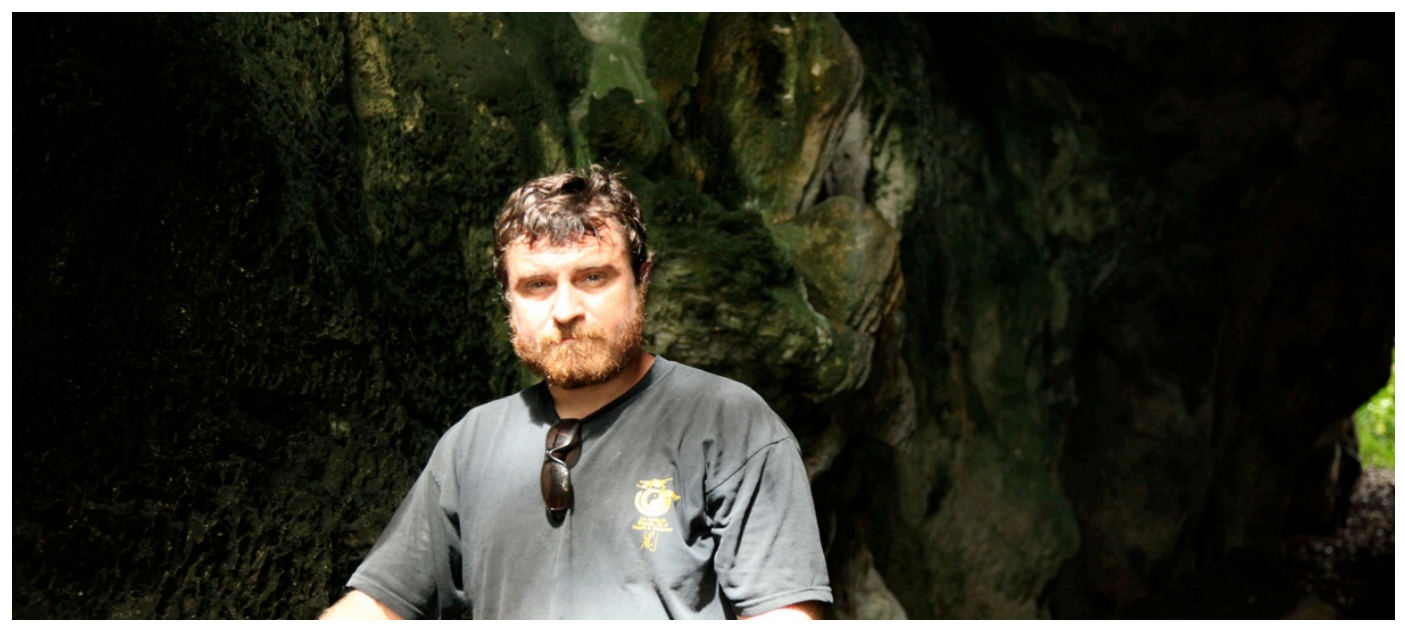


I went home and got better.

Using other people's creative drive!!!

From the beginning my creative process involved collaboration with a number of artists. I operated on the level that the creativity of the music would inspire my imagination and then, that in turn would inspire the musician. I enjoy the idea of a creative feedback loop. It was liquid, it's ripples, swells and breaks would create an open sea of exchanges.

I shared my notes with Grayson and he agreed with the song choice.

OH Stasis.

Stay with it for a moment longer.

He shared his creative impetus for the representation of the song.

The disintegration of his father's mind.

An autobiographical narrative emerged between us: Grayson's Father was always a strong man, but he had a stroke. The song is a reflection of the experience of watching the imposing physical figure of his father reduced mentally to a person who could not even feed or fend for themselves.

The disintegration of my father's body.

I related instantly. I watched my fathers body rot from the inside out because of bowel cancer. He, too, was an imposing physical person. The memory is vivid, like I can walk out the door and go up the stairs. Lay down on the carpet. And watch this man crying in pain unable to get off the couch. The man whom I loved, respected, and feared curled up in a wailing, wet ball. Emotion is the root of our mutual creative inspiration for the music. 
MY FATHER IS THE SWIMMING MAN

We were both sinking. Grayson and I.

We agreed we both saw water!!! Water in the song Oh Stasis. Where was the water?

The struggle. The swim.

The ocean. 


\section{The CITY!!}

\section{8}

It needed to be shot.

So I asked an Oscar winning Director of Photography to join the team . He did. His specialty is special effects photography, so his influence was to shoot the city as a miniature!

Also, we could not shoot the swimming man in the ocean. We needed to build a water tank.

I WAS DROWNING AGAIN!!!

It was perfect. It fits the vision of a dreamscape. It fits the sinking. The city is Bauman's embodiment of liquid modernity. The collaborators were pursuing my vision perfectly. Doing what they do best and making the best decisions to see that come true. I was scared. I thought that this project was going to be simple. Now it was bigger than me.

I was drowning!!

Still the process had to move on.

Move further.

Then I had a collaborator make them more vivid with the story board. 
Strings were pulled and we built a giant studio. It was designed by another collaborator.

I have thrown the word collaborator out several times... perhaps I will just name them all Here.

Here are some of the influences.

We shot an animatic.

The image came before the inference.

A quick aside: it may be said that a music video with water and drowning as the main theme is a cheap and easy image to create with in association with a thesis about liquidity.

No.

Liquid Modernity was found after the creative investigation of the video. Praxis helped discover the scholarly. It makes the whole thing much more powerful for the Artist.

The sinking man!!!

The struggle. The shoot!!! The Swim!!!

The technology, I had access to because of my technical experience in film. 
We were able to get access to a large professional studio. Lighting was donated by a friend at an equipment company. I was able to obtain the use of rare computer controlled motion control camera rigs. This is the technology I use as a technician. Because of this we added the Elephant shot.

The elephant shot came from an image used as emotional inspiration for the shoot. It became the blueprint for the final shot of the video. It was possible and created because we knew we had the technology needed to pull it off.

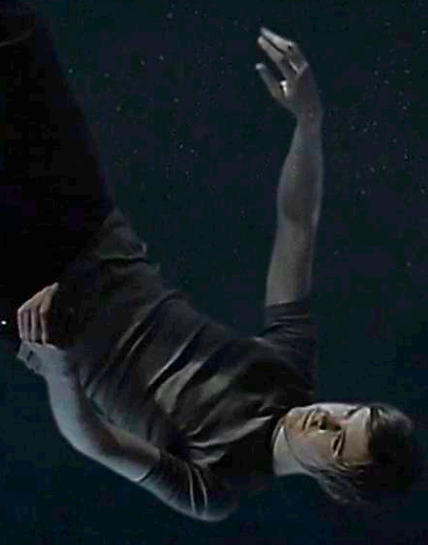


Oh by the way.... We built a water tank and a model city on the stage. It had to be big enough for our actor to swim and sink in.

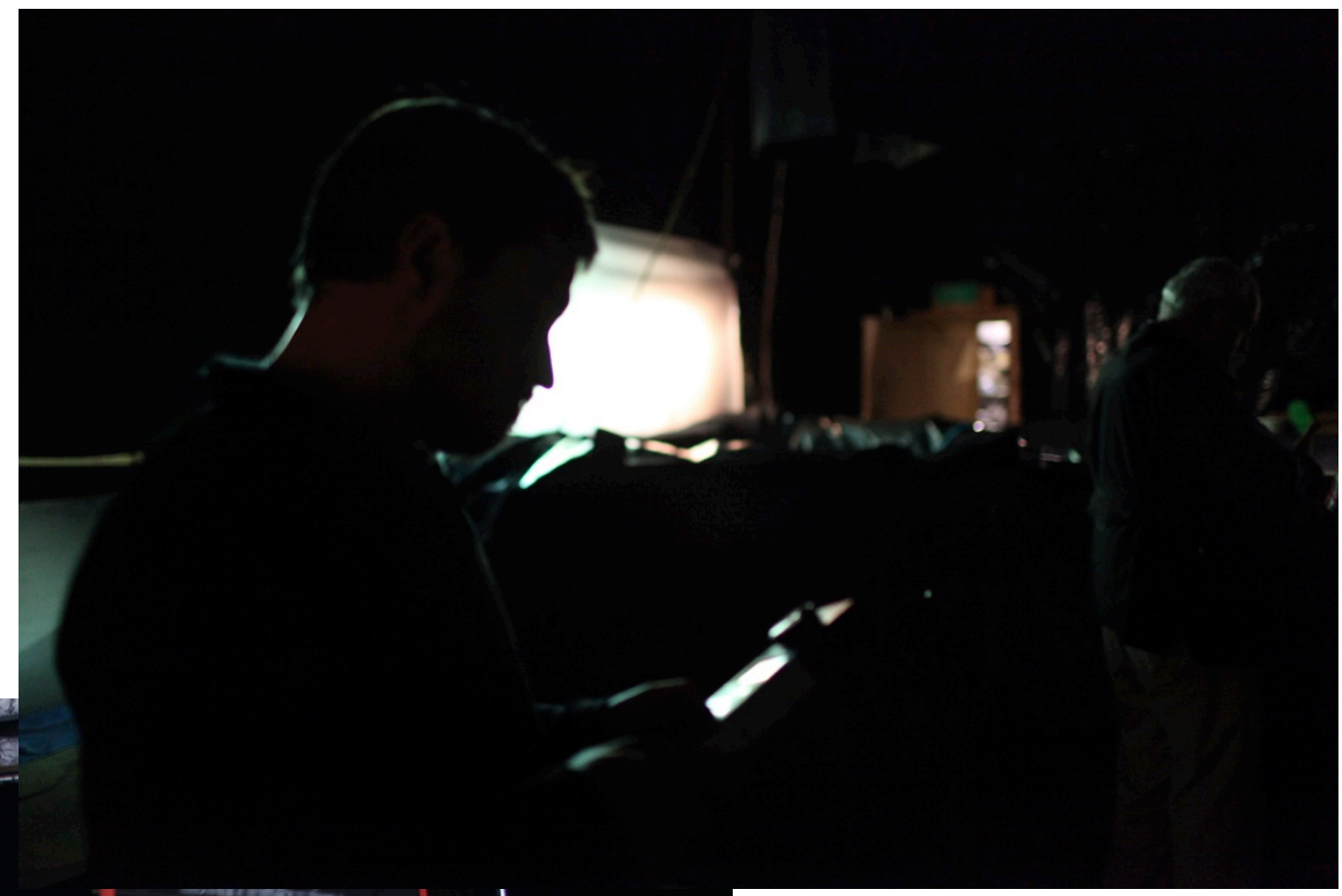


We shot it.

We edited it.

Here is a rough cut.

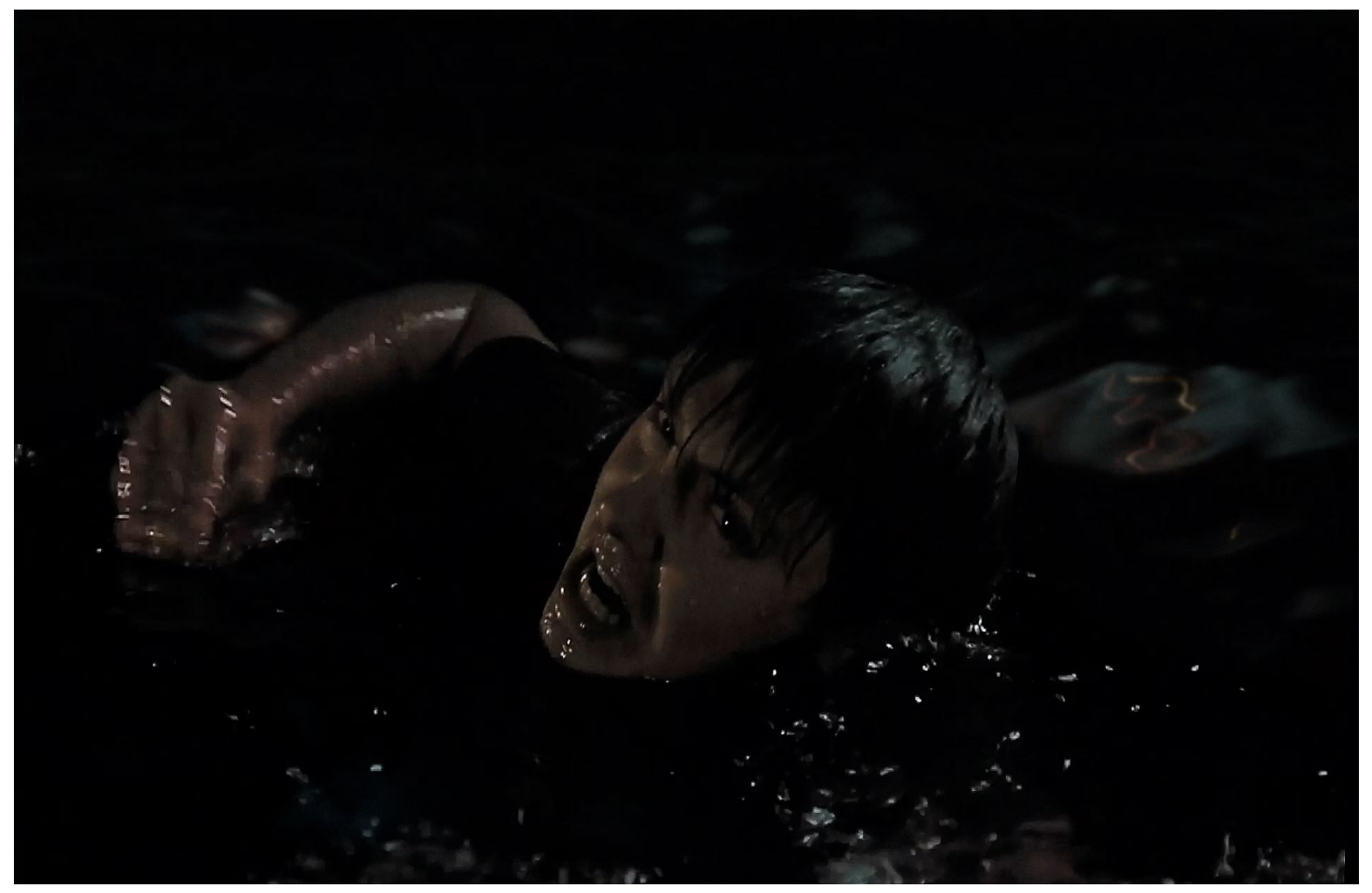




\title{
Now I have to forget these dream-logic meanderings so I can remember to write more like a traditional 'scholar'.
}

\author{
The long rant has the Author out of breath. \\ The Scholar reaches across the table with a towel in his hand. \\ SCHOLAR: \\ You need to dry off. \\ It's the Scholar's turn. \\ What was learned from the praxis? \\ What can be applied to the question of Music Videos in the age of Digital Liquidity?
}

INTRODUCTION: Or ...(where is this second chapter going anyway?)

I want to frame my praxis and research around digital video work that captures a liquid narrative. As I have already suggested, there has been a significant relationship between the expanded cinema (in this chapter the music video), technology and the idea of Liquid Modernity. Numerous authors, sometimes critically, have pointed to what has been referred to as the rise of the so-called MTV generation of filmmakers and a similar highconcept narrativisation of the music video. For example, John Caldwell discusses how the "established" industry rejected the hyperstyle that MTV production values brought to the industry. "I am suggesting that a new generation of production personnel in television is more stylistically and more theoretically inclined... many in the industry tended to view with distaste the excessive style, hypervisuality, and self consciousness of the new comer MTV" ${ }^{16}$. The multiple voices that take shape in this music video will simultaneously wrestle with the scholarly investigation and interrogate the first hand creative praxis. The voice of the 'author' will give shape to the experience of the creative, while the more scholarly voice weaves the theory into the praxis.

\section{Jump cut.}

${ }^{16} \mathrm{Pg}$ 128. Miller, Toby, and Robert Stam. Film and Theory : An Anthology. Malden, Mass.: Blackwell Publishers, 2000 p. 


\title{
We made THIS music video.
}

\author{
Me, the artist.
}

Me, the student-scholar

AND

\section{Me, The man who swims.}

There is a song, yes!!!

But there is also a video...

A Music Video through which the song sings and swims 


\title{
WHAT IS A MUSIC VIDEO?
}

The music video can be described as the preproduced video images created to accompany, emphasize, and enhance the musical artist and their song, often produced for the purpose of selling the music. The video as seen on MTV (or not seen on MTV) is a commodity intertext with a range of products on sale: the song, the artist, the album, the concert and the ancillary merchandising, to name but the most prevalent.

So it is a sales tool. YES! But is there something more? Something ancient? Something visceral? A tool that could also tap into an artists' raw creative power? As early in the history of MTV as 1984, scholars saw this duality. Marsha Kinder, an early critic of the music video saw and wrote about this dichotomy in 1984:

\begin{abstract}
"What is the significance of this Quicksilver phenomenon? Depending on which mass media reports you read, music video is a new means of extending the unique aesthetic possibilities of the adventgarde formerly restricted to independent filmmaking and video art, a new combination of music and images that redefines audiovisual relations in the mass media, a new means of marketing records and tapes that is saving the pop music industry, or a new source of violent sexist sadomasochistic images infecting the minds of our children." ${ }^{17}$
\end{abstract}

However, the modern history of the music video starts well before MTV. The most obvious predecessors of the music video are musical feature films. Imagine Disney's Fantasia $(1940)^{18}$. It is not a big leap to consider it a long form music video. There were also innovations such as the Panorama and Scopitone, visual jukeboxes, which required short form films to accompany the music of artists. Furthermore, there is also the concert footage of a live performance. One can also trace the history in avant-garde and experimental films through music visualisation. For example, the Whitney brothers created short experimental films such as Arabesque ${ }^{19}$ and Yantra $^{20}$, that many argue put them firmly in the role of innovators in the art of visualising music ${ }^{21}$. Their work spans from the 1940 's to the 1980's. There are many names that could be included in the list of progenitors of the modern music video, a discourse outside the realm of this discussion. What is arguably obvious is that music videos have a rich history, that includes Avantgarde artistic expressions and they did not spontaneously develop when MTV began broadcasting.

However, the music video has now taken on that specific meaning that we have come to associate with it. But what does the modern music video look like?

\footnotetext{
${ }^{17}$ Kinder, Marsha. 'Music Video and the Spectator: Television, Ideology and Dream', Film QuarterlyVol. 38, No. 1 (Autumn, 1984), pp. 2-15Published by: University of California Press.Stable URL: http://www.jstor.org/stable/1211862

18 Joe, Grant. "Fantasia." United States: Walt Disney Productions, 1942.

${ }^{19}$ Whitney, John. Dir. "Arabesque". 1975.

${ }^{20}$ Whitney, James. Dir. "Yantra". 1950-1957.

${ }^{21}$ Sitney, P. Adams. Visionary Film: The American Avant Garde 1943-1978. New York: Oxford University Press, 1974.
} 
I have identified five basic aesthetic styles that music videos take on.

1. Artist performance - This is simply a recording of the band performing the song. It could be a recording of an actual performance or a synthesized performance for the purpose of filming. Examples of this include Nirvana's 'About a Girl' ${ }^{22}$, U2's 'Beautiful Day',23, Run DMC and Aerosmith's 'Walk This Way'24, and Beyonce's 'Put a Ring on it, ${ }^{25}$.

2. An Artist Performance with an interlocking narrative unfolding around them. Examples of this include Radiohead's 'Justt ${ }^{26}$, Aerosmith's 'Janie's Got A Gun'27, and Guns N' Roses 'November Rain'28. In, "November Rain", for instance we follow the love affair, marriage and mysterious end of a relationship for Axl Rose, intercut with the band performing both in the narrative world and a performance world.

3. A narrative video in which the artist performs a role central to the narrative, but "sings" instrument free. Examples of this include: Michael Jackson's 'Thriller' ${ }^{29}$, The Verve's 'Bittersweet Symphony ${ }^{30}$, and REM's 'Everybody Hurts ${ }^{31}$.

4. A Narrative video in which the artists do not appear at all. These can be classical narratives with a cause-effect structure such as Fatboy Slim's 'Weapon of Choice $^{32}$ which follows Christopher Walken on a magical dance around a hotel.

5. Image/Montage based videos which are arguably forms of anti-narrative. For example, The Chemical Brothers 'Star Guitar' ${ }^{33}$ and Phoenix's 'Funky Squaredance $^{34}$. The latter being the archetypal antinarrative, Director Roman Coppola basically creates a stream of conciseness montage of text, images, and video, most of which have little or nothing to do with the song or band.

The praxis project was designed to explore a form of the fourth type of music video, the narrative. Though the narrative for the video for Oh Stasis is liquid and open for interpretation it is definitely one of cause and effect. The swimming man finds himself in the dark expanse of a dream ocean. He sees the beauty of the city, and struggles to reach it. In the

\footnotetext{
${ }^{22}$ McCarthy, Beth. Dir. "Nirvana's 'About a Girl"1994. DGC.

${ }^{23}$ Åkerlund, Jonas. Dir. "U2's 'Beautiful Day'". 2001. Island, Interscope.

${ }^{24}$ Small, Jon. Dir. "Aerosmith's 'Walk This Way"'. 1986. Profile Records.

${ }^{25}$ Nava, Jake. Dir. "Beyonce's 'Single Ladies'". 2008. Columbia.

${ }^{26}$ Thraves, Jamie. Dir. "Radiohead's 'Just"'. 1995. Parlophone, EMI.

${ }^{27}$ Fincher, David. Dir. "Aerosmith's 'Janie's Got a Gun'". 1989. Geffen.

${ }^{28}$ Morahan, Andrew. Dir. "Guns N' Roses' 'November Rain"'. 1992. Geffen.

${ }^{29}$ Landis, John. Dir. "Michael Jackson's 'Thriller'". 1984. Epic.

${ }^{30}$ Stern, Walter. A. Dir. "The Verve's 'Bittersweet Symphony"'. 1988. Hut.

${ }^{31}$ Scott, Jake. Dir. "R.E.M's 'Everybody Hurt's". 1993. Warner Bros.

32 Jonze, Spike. Dir. "Fatboy Slim's 'Weapon of Choice"'. 2001. Skint, Astralwerks.

${ }^{33}$ Gondry, Michel. Dir. "The Chemical Brothers' 'Star Guitar"'. 2002. Freestyle Dust, Astralwerks.

${ }^{34}$ Coppola, Roman. Dir. "Phoenix's ‘Funky Squaredance”. 2003. V2, EMI.
} 
end the city pulls away and the swimming man gives in to the futility of the struggle, sinking and thus transforming himself into. While the artist does appear in the video (the swimming man transforms into the drowning man at the end of the video, Grayson is the drowning man), he is not expressly identified as the artist, and serves to inform the interrogative of the clip.

How the scholarly informs the Video.

In the video I created for Grayson Gilmour's "Oh Stasis", the narrative was informed by three main filmic images: the dream world, water, and the city.

The Dream Narrative

Dreams are characterized by spatio-temporal discontinuities that are very like cuts in the film. The dream, like the film, really leaps from one place or situation or one position in a place or situation, to another. ${ }^{35}$

The dream narrative gives the viewer permission to jump to emotional and illogical conclusions that would normally need much more motivation. It also helps to establish a more metaphorical reception for the images. For instance, the image of the city within the video is obviously not a 'real' city. Bright colors and two dimensionality evoke an artificial beauty, and reinforce the swimming man's desire to reach it even though as an audience there is no surprise to its lack of stability. The dream narrative also allows for simple questions to be overlooked. Why is he in the middle of a body of water? Why does the swimming man's identity change when he sinks? The main intention for this is to put the questions the images asks before the images themselves.

The City

Owing no necessary allegiance to representational verisimilitude, such metropolis [Clifford Simak's Short Stories in the book] serves as a hypnogogic site with the anxieties, desires and fetishes of the cultures waking world and dream world converge and are resolved into a substantial and systematic architecture. ${ }^{36}$

The city has long been a key image in film studies and it has come to represent many different ideas: modernity, sociability, capitalism, chaos, control, and social castes . The research that went into the design and building of the city in Oh Stasis taps into many of these ideas. The idea of inaccessibility of the public space is a key one for the narrative of the video.

Water

${ }^{35}$ Curry, Robert, 'Films and Dream,' Journal of Aesthetics and Art Criticisms, (Fall 1974) p. 83.

${ }^{36}$ Sobchack, Vivian, 'Cities on the Edge of Time: The Urban Science Fiction Film', in Sean Redmond Ed. Liquid Metal: The Science Fiction Film Reader, London: Wallflower. (2004) p.78. 
The image of water in film is often associated with transience, thus water seemed an obvious choice to add to the video. Of the many meanings that coincided with emotional imagery that the sea brings to Oh Stasis, the two that seem most prevalent are symbolism of struggle and of fresh start, of forgetting the past.

While there are some very specific symbols that can be read by the use of these images, the ambiguity of the piece as whole will hopefully allow the audience to receive the intended emotion while developing their own personal symbolism. 


\title{
But this is research!! Did I learn something?!?
}

\author{
Something New!
}

\author{
Something Old!
}

\author{
Seeing the song!
}

\section{One needs to consider the ritual of the dance.}

Thank you very much Music videos.

Thank you MTV. (even though you no longer show videos).

Yes, music videos can be seen as cutting edge art as well as consumption driven marketing that pushes the latest styles, fashion, and fame. At first one may be tempted to believe these music videos are fully rooted in the present, In the American culture of celebrity and excess. In the realm of quirky artist pushing the boundaries of technology and taste. This assumption would be partially correct, as the videos could not come about without modern technologies of video and film production and distribution.

But there is something about the music video that isn't marketing, something that isn't a celebrity cult, something that exists in the spirit of the avant-garde artist.

Something that is universal. It is something that speaks to the visceral part of the human experience.

Span the globe, go back in time, where there have been people there have been music videos... No, not with MTV and film crews, but there were creative minds, who would add movement, colour, body, and image to music.

There is a connection between the visual displays of dance and rituals to the music video. I do not plan to divert the thesis too much down this road, as entire books and fields of study focus on the music and dance rites of various isolated cultures. There are many theories on the value, purpose and effect of these rituals, and I do not have the space to explore this further. So from this point on, I will simplify (too much perhaps) the multitude of dance and song rituals from the world into the simple idea of music, costume, and movement without the aid of modern technology as Rituals.

The music video and these rituals seem to represent similar goals: To entertain the people, to influence, to sell an idea or history, to en-trance.

Yes I am saying it, music videos have an equivalence to the music and dance rites that have been found the world over. If, we then, define the music video as a series of moving images that are choreographed with music and images intended to affect the viewers, we 
could apply the same definition to these rituals. The modern consumer culture sells the music and the start image. Rites are used to sell ideas, crops will be bountiful for instance or perhaps a dead loved one is now moving on to a different world. Choices are made during the creation of both of these as to how these representations appear, influence and make the viewer think. Larger than life representations with colorful displays of wealth and physical prowess are used to influence people's attitudes toward specific people. Quite often a powerful person such as a chief has a strong role to play in the rites creating a celebrity that reinforces his power within the community. The music video uses images to create a powerful star image. There is also a pleasurable element to both of the dance rite and the music video: Repetition of sound, body movement, and flashes of colour help facilitate a trance like viewership. It may also just be entertaining. A culture of celebrity is created around these images whether it sells tennis shoes or the power of local spirits is irrelevant.

Yes they DO have bling too.

The longwinded point here is, that MTV, videos, bling, and celebrity influence are not exclusive to modern Western culture. With a closer examination these traits of the MTV culture can be identified in many other cultures - ones without TV's or film. The moving and hypnotic image with music, I would argue is something shared by humans and expressed by whatever means available. Whatever the technology available, it seems that the drive to create and view choreographed moving images set to music is a universal human experience.

So if we accept that Homo sapiens are constantly trying to make and watch that visceral "music video", where does Liquid Modernity come into the argument? 
It borrowed from the most influential films to create a postmodern medium. The digital age has seen this assimilation spread to every visual art. The best videos can appropriate myriad animated styles from 3-D, motion graphics, computer gaming, VJaying to vivid effect. These videos can also be simplistic, stark visual haiku-bringing forth the essences of things, tracing wondrously pure forms. ${ }^{37}$

First, the transient production techniques and multi-platform delivery methods create concentric pools of opportunities and possibilities. I intend to argue that the music video is a medium in which technicians and artisans can push the boundaries of filmmaking techniques, rowing out to new seas previously uncharted. Take, for instance, the accessibility the general public has to music videos on sites such as Youtube. The videos duration is also key, where as before one would have to purchase a DVD or video, or just wait anxiously for MTV to air the video they wanted to see, now a person can search for the video at anytime. Research has been done showing the durability of videos on Youtube.

Second, the aesthetic choices made by creators can and do push the boundaries of dream logic and of the flowing, non-logical, one might say "Liquid Narrative" of its form and content. If music videos and dance rituals from remote locations are products of the same creative drives, then how are they different?

As I have already stated, artists use the technology available to create these moving music images, be they feathers and flowers or stereoscopic $5 \mathrm{~K}$ digital capturing. The liquid aspects of this modern life are what drive the liquid nature of music videos. By living in liquid modernity, the artists that exist and create within this environment are swept up by the transient currents and adapt to them or drown.

\section{LIQUID TECHNOLOGY}

Unlike feature films, videos can be less financially risky and, on a creative level, the perfect playground for cinematic experimentation; a great way to develop new visual styles or test out new technologies; in all perfect for up-and-coming auteurs. ${ }^{38}$

As the technology of music video production changes and, advances so too do the images they can produce. As the artists express themselves, they and their art are tied directly to the tools they have available to them, as the digital age changes the tools and techniques, the art of the music video, expresses the transience of the 'world' it is created in.

Leaving the Body behind.

${ }^{37}$ Hanson, Matt. Reinventing Music Video : Next-Generation Directors, Their Inspiration, and Work. Amsterdam ; Boston: Focal Press, 2006. P. 2.

${ }^{38}$ Spencer, Megan. "Thank God for Rage". (Summer 2004) in Beat the Drum . Pg.114-115. 
Most videos take place in fantasy worlds, whether elaborate depictions of other realms, or more mundane fantasies of sexual gratification and musical pleasure. These are often less about a coherent narrative, one easily translatable into words, than an effect. Music videos seek to create atmosphere, above all - a mood, and a space, that viewers could slip into time and again. ${ }^{39}$

To repeat a performance for new and more audience members, the artists had to tour. They physically had to move into a new space and time and repeat the performance. This obviously requires the corporeal body. Technology has long since had the ability of recording and transmission of a performance, allowing the bodies to be left behind. The artists can move on to create new and different performances while their previous ones can continue to be seen, with out the need for their corporeal bodies to tour different time and spaces. Ghosts of their artistic work, left behind in the ether, leaving anyone willing to spend time with the ghost, the ability to summon spirit at will. The artist is now free to explore new techniques pushing the boundaries of the art. Change comes faster. The form itself seems to change before our eyes, no longer melting at a glacial pace but like a snow flake landing on your palm.

Leaving the TV behind.

YouTube is the largest, most popular video digital library in existence, and is quite possibly the most popular digital library regardless of format type. Furthermore, music videos are one of the primary applications of YouTube. Based on our experiences of linking to music videos in YouTube, we observed that while any single URL had a short half-life, music videos were always available at another URL. ${ }^{40}$

The transient nature of the digital age has added an unprecedented rate of change to how these videos are made and presented. In a few short years, production has advanced to the point of one person filming, editing, adding digital effects, and distributing it to the world, all on one computer and for a very meager budget. From one man productions to video's that cost more than some feature films, the change has also allowed for experimenting with the tools of production. Videos such as the Micheal and Janet Jackson video SCREAM ${ }^{41}$ cost seven million dollar to produce. The director Mark Romanek developed the idea and took several months of planning and one month of shooting to produce it. From the minds of its creators, it flowed to 64 million viewers on its world premiere. But with MTV showing less and less videos the distribution of the art form/commodity needed a new outlet. No longer the TV, now we can see the video on the computer screen. Now music video will be seen by millions of people on the Internet. The Band OK Go created a video for their song 'Here it Goes Again' ${ }^{\text {,2 }}$ in 2006. The video was

${ }^{39}$ Austerlitz, Saul. Money for Nothing : A History of the Music Video, from the Beatles to the White Stripes. New York: Continuum, 2007. P 2-3.

${ }^{40}$ Prellwitz, M., and M. L. Nelson. Music Video Redundancy and Half-Life in YouTube. Vol. 6966 LNCS., 2011. SCOPUS. 9 Jan. 2012

${ }^{41}$ Romanek, Mark. Dir. "Michael Jackson and Janet Jackson's 'Scream/Childhood”'. 1995. Epic.

${ }^{42}$ Sie, Trish and OK Go. Dir. "OK Go's 'Here it Goes Again”'. 2006. Capitol. 
a one take choreographed dance on several treadmills. The video became a hit on internet mediums such as YouTube with 50 million views. They were awarded several Grammy's that year, arguably that would not have been possible without the internet released video, no television set required.

Leaving the Music Video Behind

\begin{abstract}
Music videos have started showing up in forms that belie the confusion of music video (as a form) and music television (as a delivery technology for that form): music videos now come to us on DVDs and enhanced CDs; on PDAs, cell phones, and other wireless communication devices; and, perhaps most importantly, on the internet. $^{43}$
\end{abstract}

The music video no longer constrained by the 'rules' of television viewing, the music video itself is changing forms. The freedom and technological innovations that internet distribution brings allows for content and form evolutions. Rammstein, a well-known German heavy metal band, broke music content conventions with their video 'Pussy'44 by showing explicit, penetrative sexual intercourse on their video. The taste and social impact of a mainstream band creating a video can be argued; but that they broke boundaries of what was considered allowable for a music video cannot. Kayne West has also recently taken advantage of freedom that internet distribution has allowed by creating a feature length 'art' film music video for 'Runaway' ${ }^{45}$. But the real changes in the form of music videos one just needs look at the Arcade Fire's collaboration with Chris Milk called 'The Wilderness Downtown $^{46}$. It uses the Internet technology of HTML 5 to produce an interactive experience set to their song 'We Used to Wait'. It is no longer a video for a song, but a unique experience for the viewer, that takes place on the internet. The Video has evolved. Bjork has taken her entire next album in a new direction by releasing it as an application for portable electronic like the iPhone. The Biophilia ${ }^{47}$ App takes the ancient idea of visualizing the music and seeing the song, to the next level. The album has evolved... seeing the song has stayed the same as it ever was. A dream of or in our mind.

${ }^{43}$ Beebe, R. (2007) 'Paradoxes of Pastiche: Spike Jonze, Hype Williams, and the Race of the Postmodern Auteur', in Beebe, R. and Middleton, J. (eds) Medium Cool: Music Videos from Soundies to Cellphones, Durham and London: Duke University Press, 303-327.

${ }^{44}$ Åkerlund, Jonas. Dir. "Rammstein's 'Pussy"'. 2009. Universal.

${ }^{45}$ West, Kanye. Dir. "Kanye West's 'Runaway"'. 2010. Roc-A-Fella, Def Jam.

${ }^{46}$ Milk, Chris. Dir. "Arcade Fire's 'We Used to Wait (The Wilderness Downtown)"'. 2011.

Rough Trade, Merge.

${ }^{47}$ Björk. Prod. "Björk's 'Biophilia”'. 2011. One Little Indian. Polydor. 
NOW!!! I HAVE A VIDEO!!!

Not quite!!

The Scholar stands. His cheeks are red from the effort of drying things out, the Author is indeed now dry.

The Author rises from the table, nods at the writer who has stealthily materialized some time in the past few minutes, then steps out of the room.

In the doorway he turns.

THE AUTHOR:

The post production: or how I learned how to stop depending on CGI and do it in the camera!!!

Then... 


\section{ONE YEAR LATER!!!}

Yes that is a long time.

I have realized that unless I have the money or technical skills to shift the creation point to post production (see chapter one) most of my creation process needs to take place in camera. 
Here is my Vision for seeing the song.

Did it work?

What did you feel?

That's enough for now, but before I go...

Will you watch me melt?

\section{END OF CHAPTER}


The Author melts. The Scholar lays his head on the table and sleeps. The writer...

... just types. 
The writer keeps typing... while the scholar makes tea from a pool on the floor that is the author. He scoops up the author and pours him into the kettle, places the kettle on the stove and lights the fire. The writer looks up and smiles. The scholar is not amused but the author starts to whistle a happy smile from inside the kettle.

They drink the Author with some biscuits and sugar.

The scholar pushes the writer aside and begins to type at the keyboard. An image appears on the screen, it is an image of the scholar. The scholar waves and the image waves back.

INT. THE COMPUTER - CONTINUOUS.

The Digital Scholar waves again. He sees the fleshy scholar press another key.

The Digital Scholar's hair grows long and straight.

The Scholar presses a key.

The Digital Scholar's face rounds and his skin softens.

Another key.

A beard grows in seconds.

Key •

Round breasts develop.

Key •

W

Key •

0

Key •

$\mathrm{M}$

Key •

A

Key •

N. 
Yes.

I am...

Becoming a woman.

There is a thin film between you and me. Air escapes my lungs and bubbles on the surface. My face breaks through this thing that divides us.

I am...

The Surfacing Woman.

not quite ... 
Here WE go ...

A font much more becoming of a surfacing woman.

I am ... 
The

Surfacing woman. 


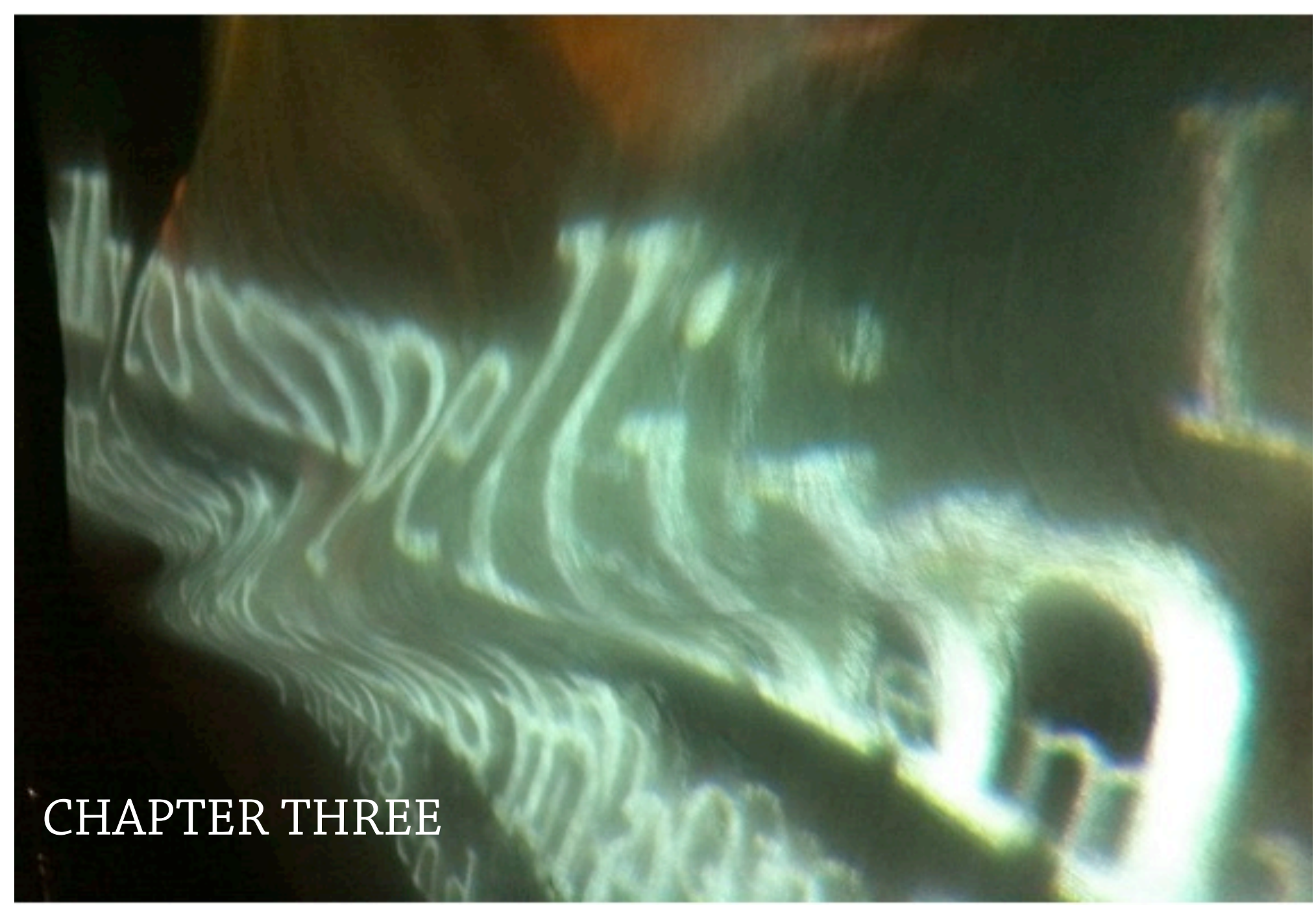

The Artist arrives.

THE ARTIST:

Let's get this right.

The Artist puts her hand on the shoulders of the Writer and

Scholar. They start to... finish.

Where is This GOING now??

In this final chapter, I will discuss how digital technologies affect artists working in the medium of installation. I will also discuss how my practice, the installation piece entitled "drown", was infused with digital life. Finally, I end the chapter by bringing the idea of liquid modernity into the analysis of this thesis and my praxis.

We have had a time together, all of us.

You, me (The Surfacing Woman) and the others. 
We have created many people, many things, many ideas.

It has been a fun ride, but now it is time to pull together all that has been written and created. We see the finish line. It is close.

But let us stop for a moment and take this new path over here.

It is time to do the opposite of what might seem appropriate at this point. If at this moment you are reading this thesis on a computer, or an $\mathrm{PAD}$, or some other electronic device, I ask you turn off the power, unplug the machine, and go offline.

Now, pick up the paper version of this.

It might seem that by literally going back to the written page I am taking this electronic thesis in the opposite direction to that which it should, undermining the work we have done. The idea of going back to paper, antiquated matter, in a thesis that emphasizes technology - that in fact suggested using technology to experience this thesis - is a wrong turn. Not so!!!

There is a something that is sublime, ethereal, ghostlike, that sits at the heart of all "things", be they creatures, or films, or art, or even the pages of a thesis. The closest word to describe it is "soul". In between the electrons of the technology we have been talking about, and the reality that exists in the atoms of a piece of paper, is the hunting ground for the soul of this thesis. It is a very difficult quarry to stalk. Paradox is the bait we will use. And hopefully by the end of this chapter together we will have found the soul of the thesis and the praxis.

The idea that the online persona, all electronic pulses and liquid matter, that shifts and changes in a moments notice, is more stable than the organic one, the" real one", is not the most obvious conclusion to come to. But, follow this train of thought for a moment; think of the electronic device that you may be reading this on. Computers and electronics are the exemplars for fragility. Keep them away from water. Do not drop them. Do not shake them. Keep them away from magnets. Beware of viruses. The list of warnings and ways to destroy these devices are numerous. The information inside the computers are fragile as well, or at least they used to be. We are now at a point with technology where data is automatically backed up and saved to the cloud. Servers in a building thousands of kilometers away automatically store the information for you. Now the words can live on forever. As long as we hit the save button, back it up or let the computer do it for us, there are no worries, no fears about losing the words.

And yet,

There is something sacred about paper. 
Something magical about a book.

If we set this paper on fire, if we burn the book the words could be gone forever. We cannot just download another piece of paper. The fragility of that paper makes it special. The lack of the digital simulacrum allows the paper in your hand to be special. The paper is the authentic result of the moment of writing.

Now mind you, this whole line of thinking falls apart when we read the statistics about the life of vellum and papyrus versus current digital mediums, but that's okay, paradox is good.

Imagine the ethereal or non-corporeal persona. Remember the made-up persona of the author that we created together in the 1st chapter. Part of him/her can live forever, the part of him/her that was represented by letters on your screen, the part that can be downloaded and emailed. The author that was created in your mind, that voice, that face (if there was one) at that moment in time can never be repeated. It happened once and never will be repeated. So in this one persona we have immortality and instant eradication. Time moves ever forward and does not stand still for us.

Cinema, the MOVING image, is a time-based form, "Expanded Cinema" and specifically, Installation art has given us a different take on this movement.

The paradox: new technologies are able to reveal the beauty of cinema, but through a displacement that breaks the bond of specificity so important to my generation of filmmakers and theorists.

Furthermore, particularly through access to cinema's stillness, new technologies allow the spectator time to stop, look and think. This process opens up the possibility of a link that takes the kind of theoretical reflection developed for an analysis of the still photograph to a new relevance for the moving image. ${ }^{48}$

Consider the organic person writing this thesis, the person who chooses now to be a woman, to be flesh and blood. Once that organic person dies they are no more. They are or were only ever liquid identities, with a dehydration date. By contrast, the inorganic, "unreal" state that lives in the digital world lives on frozen in time. For example, I may create an online persona for a game or a message board. All the conversations, all the recorded data, all the statistics are stored for that digital persona. The data that IS that persona exists, perpetually, as long as something exists to retrieve the data. That persona lives in the ether. But, when the organic state dies, it is gone forever. Any reconstruction, be it from memories of the living, or photos or written anecdotes or even those digital selves that the person created in life, exists as different from the original. And yet,

\footnotetext{
${ }^{48}$ Mulvey, Laura. "Stillness in the Moving Image: Ways of Visualizing Time and Its Passing" in Saving the Image: Art After Film. Eds. Tanya Leighton \& Pavel Büchler. Glasgow: Centre for Contemporary Arts, 2003. Pg 81.
} 
Life is fragile.

I want the paper in your hands to feel fragile.

I want the words to seem fleeting as if they'll go away at any moment.

Just like the fragile body of an organic human being. I want them to be dear, I want there to be an emotional attachment.

The digital copies of this thesis present themselves much like the myriad of online digital personas and can be recalled. The safety of the digital back-up breeds a complacency. Fragility creates a sense of preciousness and value. Humans tend toward the opposite of nurturing and cultivating the part of our being that gives us this special meaning, paradoxically we seem to strive for the antithesis, immortality instead of rarity. We try to save and back up. We try to make our permanent mark on this world. We want to be remembered, but this robs us of the rarity that makes life valuable. Pier Paolo Pasolini discusses a similar idea in his essay on long takes.

\begin{abstract}
It is thus absolutely necessary to die, because while living we lack meaning, and the language of our lives (with which we express ourselves and to which we attribute the greatest importance) is untranslatable: a chaos of possibilities, a search for relations among discontinuous meanings....It is thanks to death that our lives become expressive. ${ }^{49}$
\end{abstract}

It is in this sense of fragility and transience that the artist did her work on the installation piece. The loss of our very identity, the true loss of ourselves, is the very thing that gives us meaning and value. The exploration of various forms of loss and shifting identities are the core of what Amy Audubon presents.

We are shifting from technology to the organic, the ideas presented in this thesis are shifting. In the first chapter I wrote about the moment of creation shifting due to the digital age. I explored the idea that we no longer create with the opening of the shutter, but instead creation happens over time in the computer. The moment is extended. Then we explored how the music video is an exemplar for the creative experiments made possible by emerging digital technologies in filmmaking. Now we are searching for the "soul" of the thesis through an exploration of the identity of the artist as it resurfaces in the installation piece.

\footnotetext{
${ }^{49}$ Pasolini, Pier Paolo, "Observations on the Long Take" in The Cinematic, Documents of Contemporary Art. Ed David Campany. London

Cambridge, Mass.: Whitechapel ; MIT Press, 2007. Pg.86.
} 


\section{A Journey in three parts: Encountering The Installation.}

The power of threes is a dominant force in the universe. I created / found / rationalized three encounters in the installation in four steps.

The first encounter the viewer finds the installation on their own terms, at home, on the computer, on the phone. The viewer brings the art into "their space" at a time of their choosing, like piping a hot shower in. They do it here on this web site.

www.drowninstallation.com

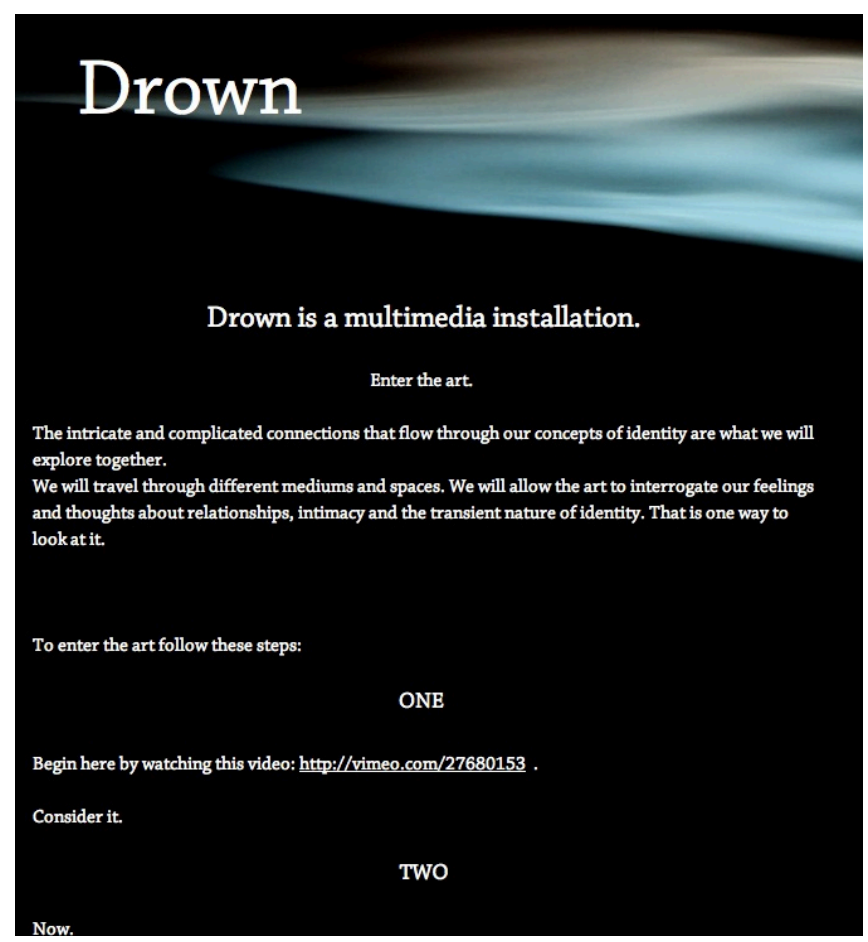

Why is this significant?

The short film "drowning man" pours onto their screen when they want and they can look at it at their convenience. The scheduling of time is no longer fixed, regulated by the broadcaster, rather one time shifts, there is no need not worry about missing the experience. They come to the short film on their own terms.

After viewing the viewers are asked to respond in text to the short film.

"Now.

Respond to the video with a few brief words you can write in the space below. If the video is a question then answer the question it asked you.

If the video caused an emotional reaction then write it down. 
Rate it.

Be artful.

Be childish.

Be fake." 


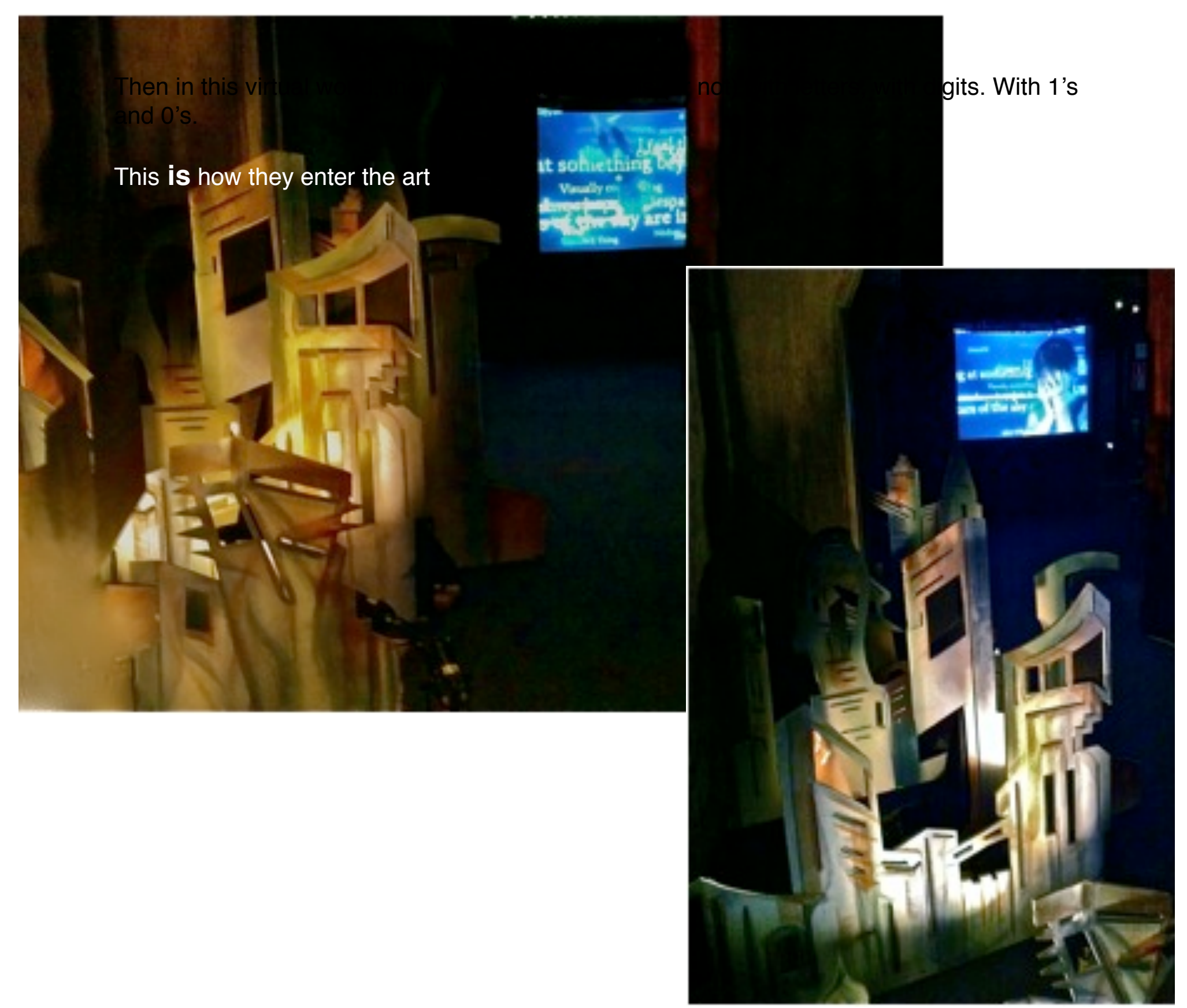

If taken, the second encounter with the installation is outside one's personal space, outside the safe space that is the viewers home. The viewer must physically travel to the installation. The traditional Installation is a more established art form, and with its history comes expectations. These expectations come forward and the anonymity of the digital self is left behind. The viewer enters the exhibition space and they are confronted with the wooden flats used to create the city in the video. The dreamlike city of the digital world confronts them with its firmness, with its tricks, with its splinters. The deconstruction of the video starts the interrogation in the space. As they pass the city on a flowing and semitransparent surface is the large image of the drowning man sinking slowly in a sea of the very words that the viewer used to express their answer to the first viewing of the drowning man video. 


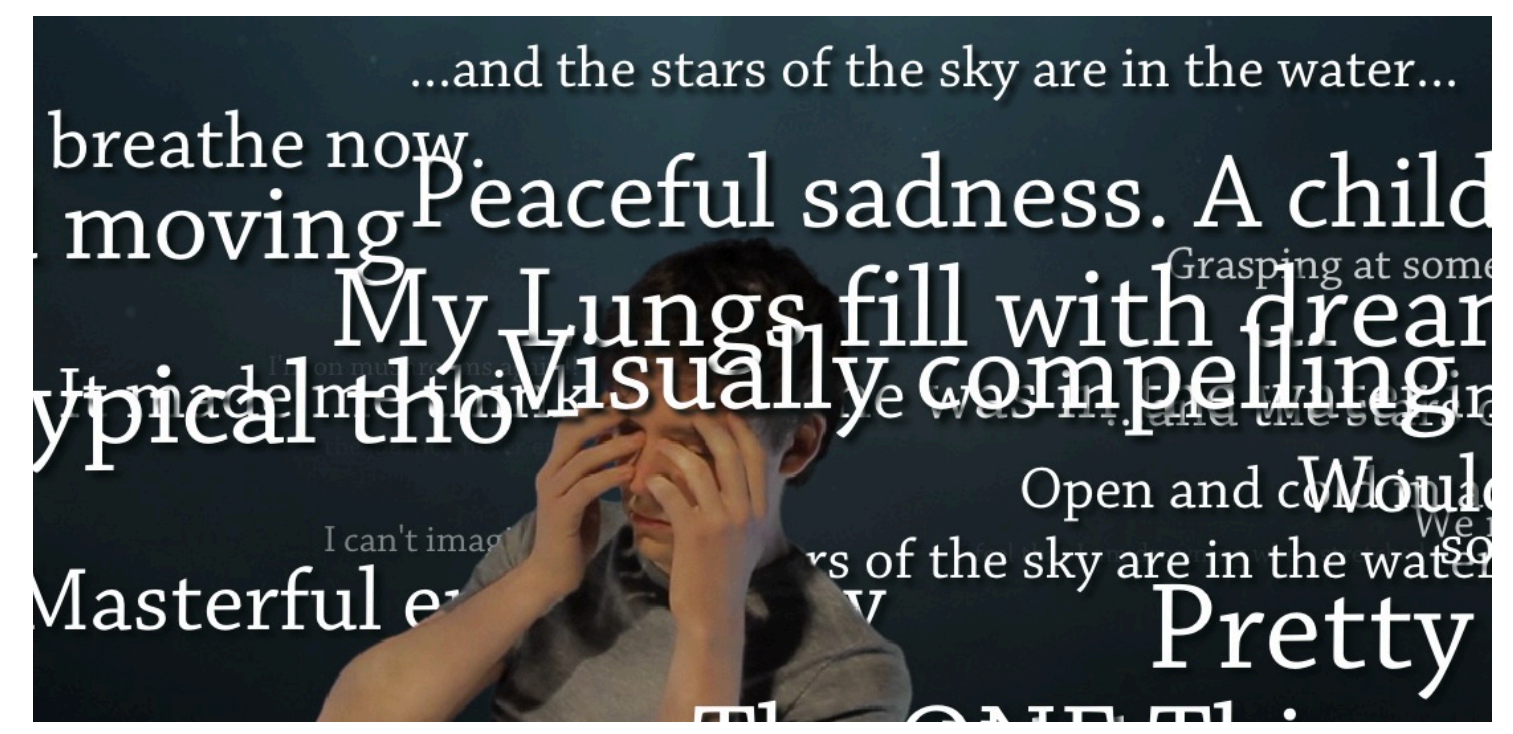

They experience the liquid poetics and politics of art in the public space; viewers may not feel safe without the anonymity of the web to protect or conceal them. But it is also the place where they can feel the heat of the photons on their hands.

They can feel the splinters of the city entering the fleshy pads of their fingers. They can meet the gaze of strangers, experiencing the answers they gave too. Or different answers to the same question(s) 


\section{1}

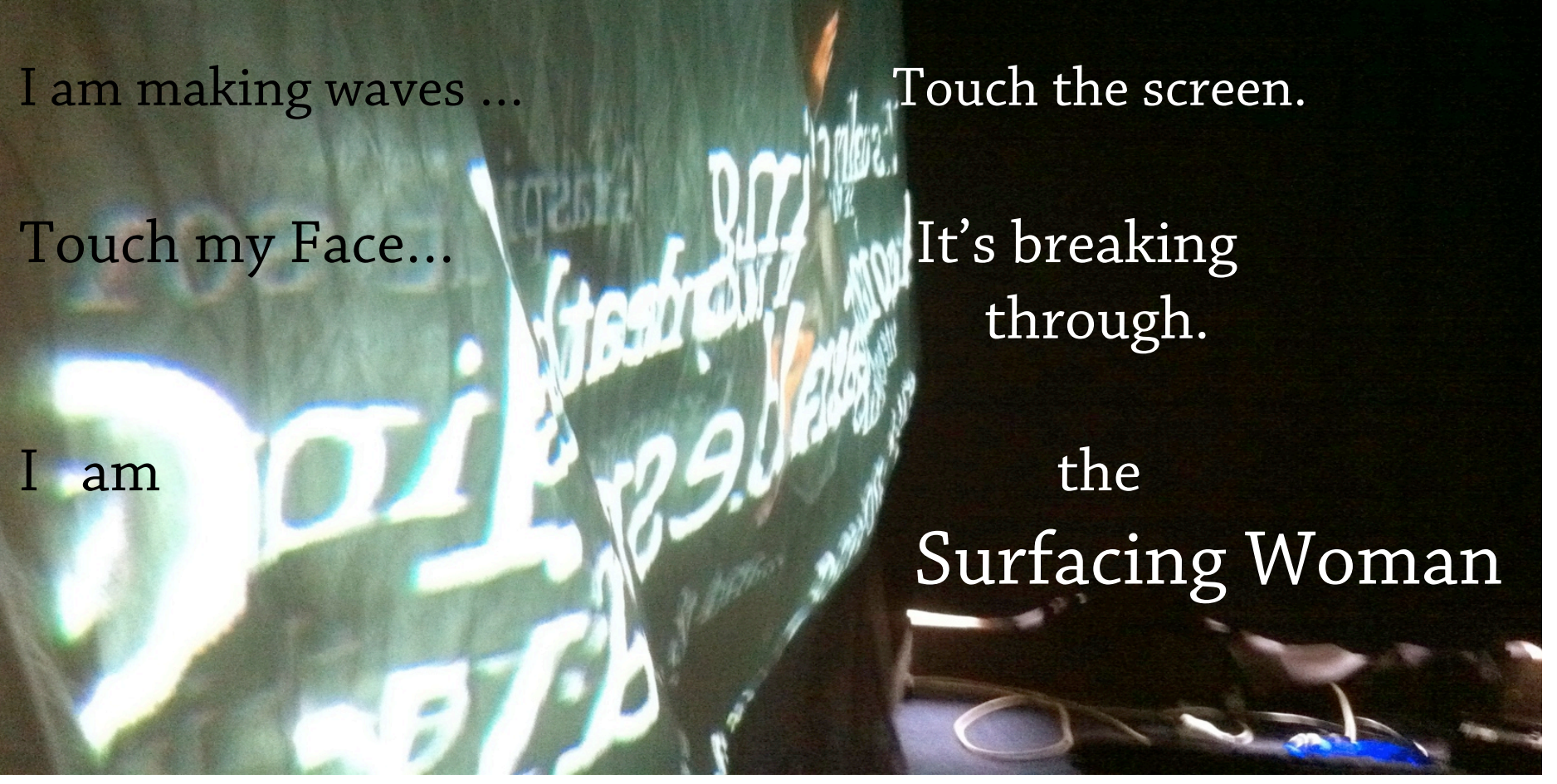

Next they are invited to move forward into the room, from this perspective they see the deconstruction of the piece. They see backs of the city, bare unpainted wood. They see the projector spraying the image of the drowning man. The magic of the constructed image is broken down.

Now the viewer is asked to move out of the exhibition room, and into or through the space with the city and the figure of the drowning man. They are encouraged back stage, of both the art and now the space itself, a theatre. The artist deconstructs the short film the installation and space on the journey to the final encounter. 


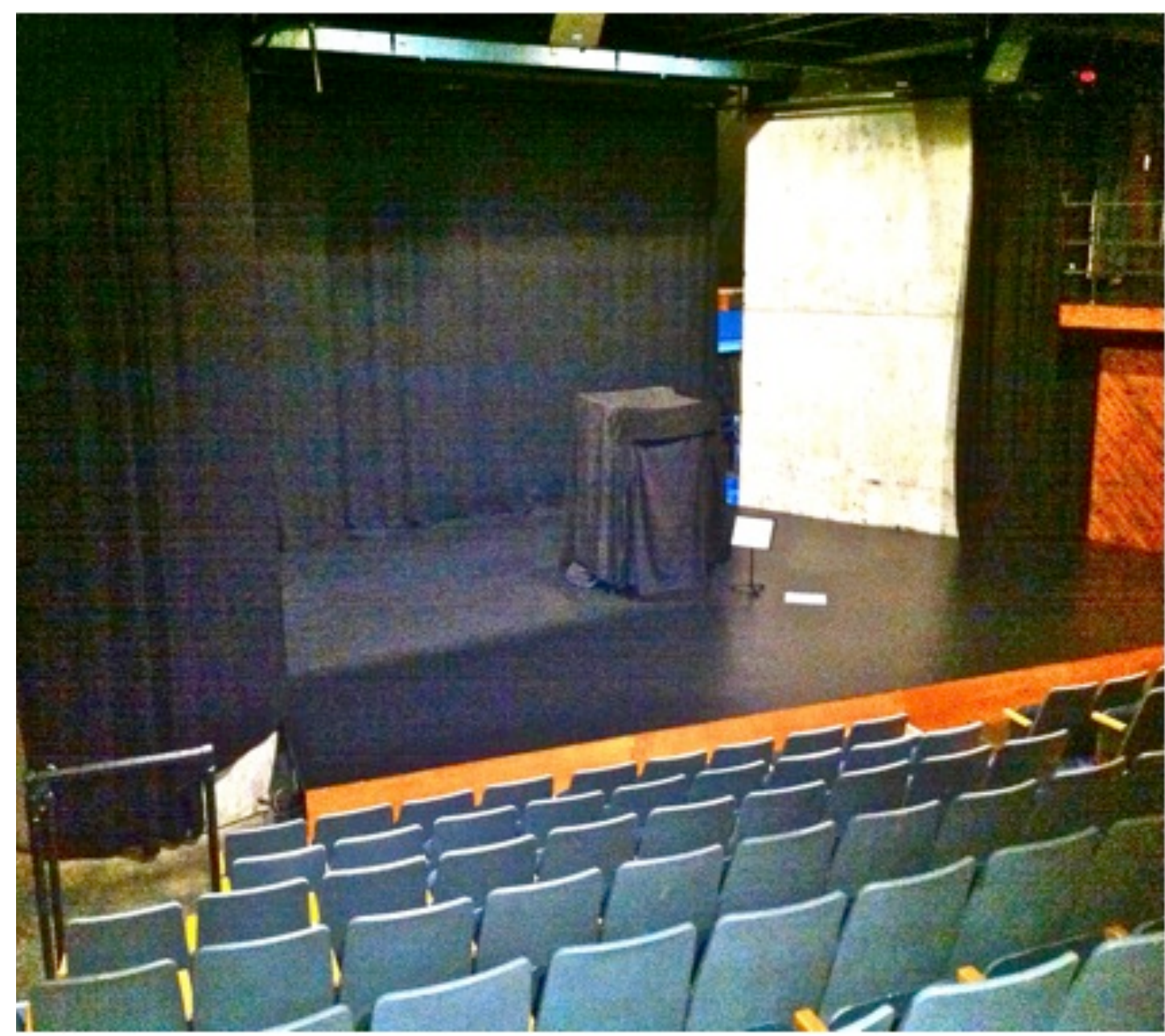

The final encounter is the question again; it is the video "drowning man", but this time, presented in a different space and with different circumstances. The viewer enters a theatre and on the empty stage is a small black draped booth inviting them in. In it, "Drowning man" cannot be stopped or played according to the viewer's desires. The viewer is purposely isolated from distraction by using a constructed device that blocks out sound and vision emanating from the outside world.

In this viewing there is nothing but the viewer and the video, and importantly the viewer is not in control of the image.

The image plays on.

Now, the viewer meets the short film on the short film's terms.

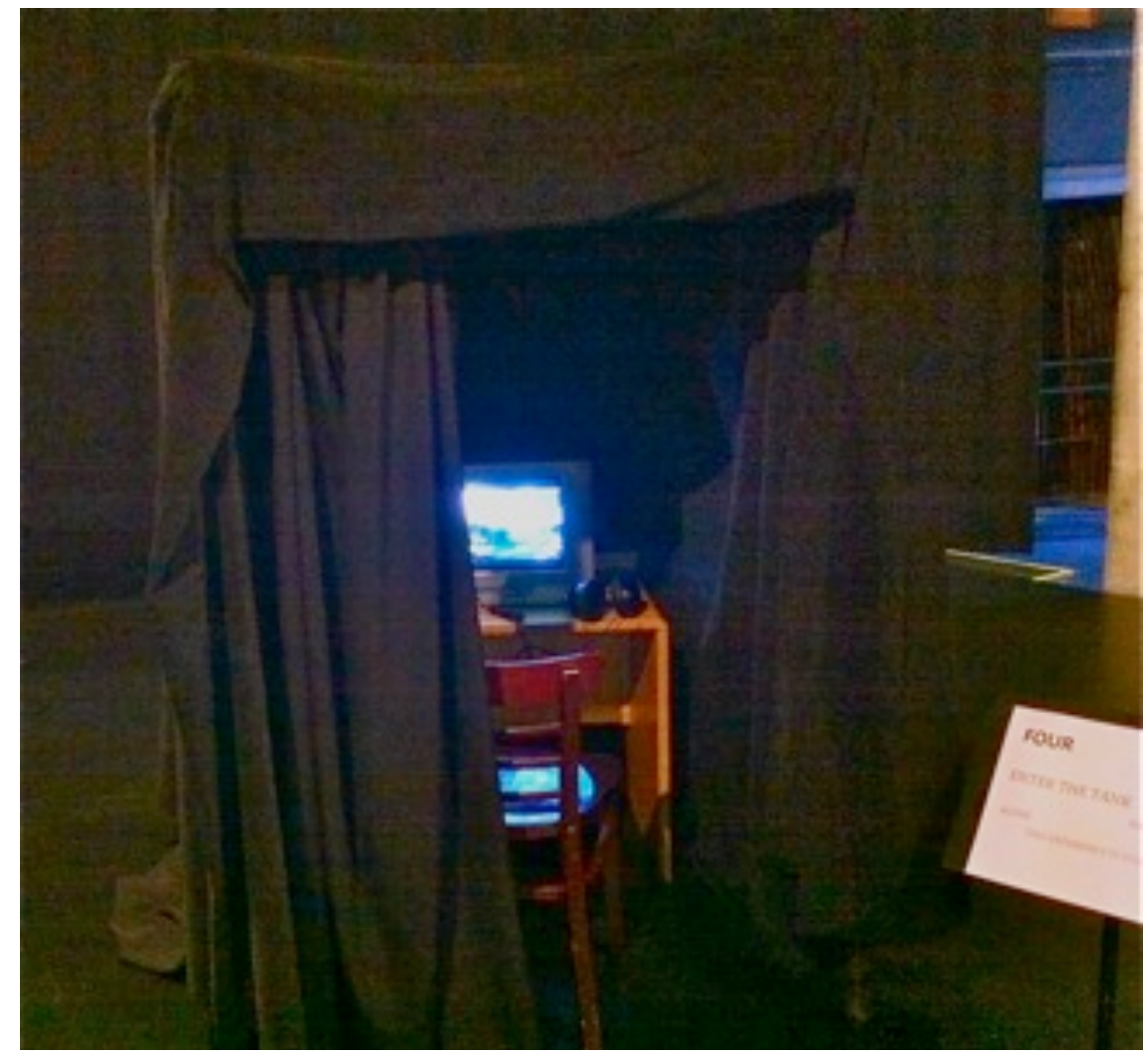


The viewer hears nothing but the music, sees nothing but the image. In this place, the audience encounters the question, and the encounter itself becomes the answer. The thoughts of being separated from the video flow away and experience becomes the thing. They become experience. They become the question. They become the answer. They and the video become the body without organs. But more on that later... or now if you skip ahead.

Experience it again.

The Installation locks the moving images in a time and space. The images are locked with the experience of the viewer. It is not just about images sounds movies or art, but about space it is in

where you stand

who stands with you. 
Remember the me!

\section{I am}

\section{The Surfacing Woman}


Here are some notes on my piece:

\section{Part 1:}

I've always been told that art should stand on its own. But then again I've never been one for fine art.

When I do these pieces, this arc, I think of my mother.

She's never had an education in fine art. She never learned the vocabulary. She's never been told how to approach it.

That is why these art had instructions. This is why it had directions. Because I believe anybody can come to art and appreciate, they just have to know the language.

This is something intimate about entering art, or if you will become art. By allowing the viewer to have their own words added to the art in the first part of the piece, I'm hoping to engage in a sense of intimacy.

At the same time, hopefully, I intend to question how intimate can one be with someone or something else when he/she is constantly accessing through medium, specifically the medium of the Internet creating a barrier through which the intimacy must occur. I can just imagine a roomful of flatmates sitting around the TV each with a computer in their lap. Never making eye contact. Never opening their mouths. Just clicking away at the keys sending each other messages, IM's, photos, and links.

Is this intimate?

When they come to the film how do they find it? The country on their own terms they can hit play they can hit pause they can resize it they have the control.

Then I asked them how it makes them feel.

Is this intimacy with the image? 


\section{Part 2:}

The image on the wall in the space.

Appropriated from music when the digital age makes appropriation easier.

Yes, it is the same image as the web site, but it is different. It is in the space!!! It is on the wall. It is here now!!! You can touch the photons as they bounce in the space. The sound waves bounce off the bodies in the space.

The body can interact with the light. The skin can be warmed by the light. The chest can vibrate with the bass of the noise.

Isn't this more intimate than a web page?

But there are others here with you. You are not alone with the piece.

The city is meant to bring home the reality of the construction of the film, or perhaps more appropriately the deconstruction of the film. The image of the drowning man on the screen slowly sinking, sinking in the words of the people who responded online was a part of the piece that several viewers commented on. Comments along the lines of, while standing in a room of strangers they felt oddly connected to the people. They could see the words of other people the thoughts of other people. Things that they hadn't considered themselves there on the screen, and it brought home that the connectivity of everyone involved. The screen itself is made of a semitransparent material flowing and see-through adding to the liminal liquid space of the entire piece.

The sounds of the song from the video fill the room.

And finally the audience is invited past the screen exposing all the secrets, all the machinations, again deconstructing the piece as they move along by travelling backstage, not only of the piece but of the theater itself.

\section{Part 3:}

We have the left the space. Now we are faced with a strange device. 
After traveling backstage the audience enters an empty theater and they're presented a small booth on the center of the stage.

A Tank.

Inside it, playing on a small television set is the short film the drowning man. Instead of coming to the video on their own terms, the viewers come to it on the terms of the film. They can't stop it, nor can they make it move forward, or backward. They are there at the whim of the film. The question I wanted to ask the viewer is: does this change the experience? Is it a different experience? Does the fact that the viewer is in this booth, private and isolated from outside distractions, enter the mind?

Whether people outside staring at you see the curtains of the tank?

You are alone when you see it.

Hidden from the others.

No one else can see the screen or hear the music.

Does knowing this "video" has played on screens before, that anyone can look it up online and see it whenever they want, take away from the fact that no human will ever have the exact experience that is taking place in the right now, in this place, on this date at this time as you alone watch the video.

Because right now it is just you and these images and sounds, you alone shared with no one that ever WAS or EVER will be.

Where do we find the intimacy and relationships in the digital ever-changing age?

Is it in the company of others?

Is it with an interface?

Is it with ourselves?

Finally, left in the tank is a handwritten note for me to the viewer.

I wanted to thank them.

I wanted to let them know how special they are and how special this moment is when they share with my art. In this time and place they have experienced something no one else in existence can. In all of the universe, that moment is unique to them. 
I want to take a ride with Deleuze

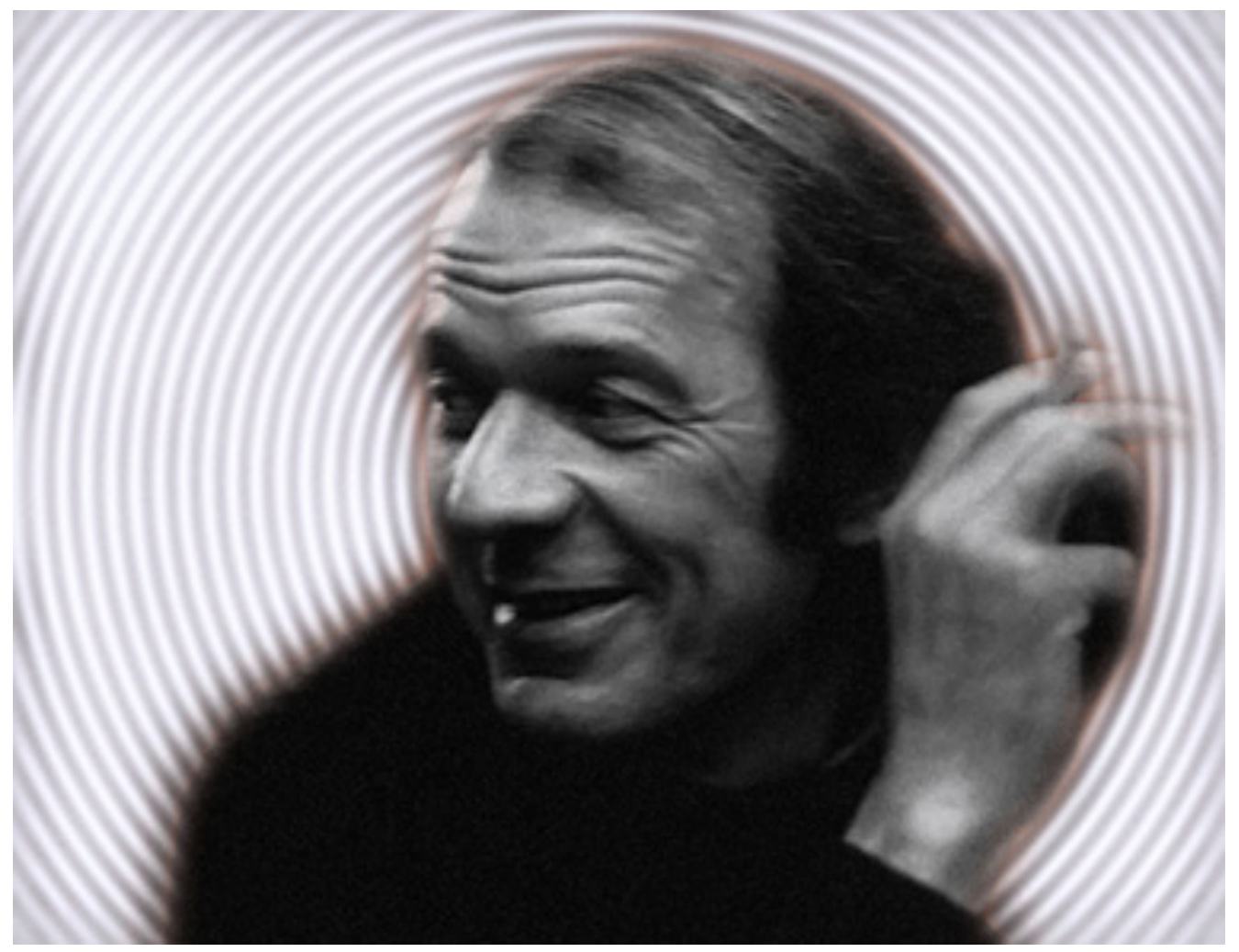

Riding Deleuze 
Much like our friend Bauman, Deleuze and Guattari have looked at the idea of changing your persona, be it subconscious or conscious. They call it "Bodies Without Organs" or BWO. I won't pretend to be the definitive authority on what they meant by BWO. Many words and sentences have been created trying to explain and understand the concept... What I will convey is my experience of reading about BWO. The "reading" although is perhaps not the best term. Probably "ride" is better.

The very artistic style in which they wrote their book "1000 Plateaus" demonstrates they were more interested in evoking a feeling and showing a path, than they were in explaining a concrete formula. Take this excerpt for example:

\begin{abstract}
What happened? Were you cautious enough? Not wisdom, caution. In doses. As a rule imminent to experimentation: injections of, caution. Many have been defeated in this battle. Is it really so sad and dangerous to be fed up with seeing with your eyes, breathing with your lungs, swallow with your mouth, talking with your tongue, thinking with your brain, having an anus and a larynx, head and legs? Why not walk on your head, sing with your sinuses, see through your skin, breathe with your belly: the Thing, the Entity, the full Body, the stationary Voyage, Anorexia, cutaneous Vision, Yoga, Krishna, Love, Experimentation. ${ }^{50}$
\end{abstract}

These quoted words are not simply step by step instructions to enlightenment. The words, the sentence structure, the choice of images are clearly meant to elicit emotion more than an intellectual reasoning. And much like Buddhist koans, the meditation of the paradox of walking on your head etc. is meant to stop your brain from trying to find any logical explanation for the writings. Instead your creative mind takes over to come to terms with the words in front of you. The poetry of the words evoke emotions more than the meaning of the words bring about explanation. My journey with Deleuze and Guattari brought me face-to-face with my desire. Brought me face-to-face with my body without organs.

For me, this is the point of creating a BWO; one's personal journey; something that is only truly attained by the experience of reading the words, not through explanations from another person. It is only found by the act of creating the BWO.

Zen monk Mumon Wumen Huikai has a similar idea in his thoughts about enlightenment. Now how does one pass through the gateless gate? Some say that whatever enters through a gate is not family treasure, that whatever is produced by the help of another is likely to dissolve and perish. ${ }^{51}$

How long will I stand on the outside? I can read. I can ponder. I can talk with friends. I can email experts. Until I create a BWO, I am only standing on the outside looking in. Creating a BWO is walking through the gate.

As I read, vulgar words put images in my head. I felt strange and awkward, perhaps a bit embarrassed. I wanted to "understand". So I reread, thinking perhaps I missed a key phrase that unraveled the whole mystery. There was still embarrassment but there were also words that changed my feelings. Now perhaps the thought of a sexual encounter that involved the smacking of a bottom was also arousing. I wanted to understand, so I let in the desire that my embarrassment previously kept away.

50 Deleuze, Gilles, and Félix Guattari. A Thousand Plateaus : Capitalism and Schizophrenia. London: Athlone Press, 1988. Pg 167.

${ }^{51}$ Reps, Paul. Compiler. Writings from the Zen Masters . London : Penguin books, 2009. Pg. 3. 
I felt that desire well up. So I read again letting in my desire in order to change understand into understanding. I created a BWO with my desire to create a BWO.

I know. I know. "What is the sound of one hand clapping? " is rather cliché, but this meditation on BWO was truly my way in.

In a piece about transformation and transient identities understanding how to become is, in my opinion, essential research. BWO is desire. What happens when we no longer desire things but desire self? We have lost our selves, we have changed our selves, but there is no map back. So we have to keep changing. BWO is the desire of desiring identity.

This is why BWO is important in art, it frees one to explore art from places that perhaps we were too scared to go before the transformation. David Fancy sees potential in the writing, here is what he has to say about it:

The epigraph draws our attention to Deleuze and Guattari's rejection of normative notions of talented identity and subjectivity in favor of something more expansive, multiple and, ultimately, more playful. In this thinking around subjectivity, identity and individuation, Deleuze and Guattari turn away from the possible-that which on some level has already been conceived, such as the normative bourgeois individual subject or any other self-contained object of scrutiny-towards that which resonates with unexpected potential. ${ }^{52}$

The 1 and the 0 of the digital age are the new tools of this self-transformation.

So Now I type and 1's and 0's change me.

I am the artist.

I am drowning in my own organism.

I leave the white middle class male guilt behind. I am free of those shackles that have made me the master.

I am an artist.

I am a woman.

My body is created in the exquisite joy of sharing my creation.

I am a BWO. I am the experience. Becoming

EGG

52 Fancy, David. Difference, bodies, desire: The collaborative thought of Gilles Deleuze and Félix Guattari in Science Fiction Film and Television - Volume 3, Issue 1, Spring 2010, pg. 93. 


\section{The Liquid Nature of Digital Technology}

Don't worry, Mr Bauman is still here, so is his Liquid Modernity. For what better expresses the Liquid nature of today's Identity than leaving the organism behind and creating a BWO. So far, in this thesis I have created several BWOs, mostly through the pleasure of ART, a few ? through the masochism of writing this thesis when my head wasn't in it, and some through the panic and relief of deadlines. "Why did I volunteer for this? Why am I paying thousands of Dollars for a Degree that will most likely not advance my career in any meaningful way." The pleasure of creating, and discovering, and the pain of the unkown and self doubt. These have all been BWOs. So In Liquid Modernity we CAN shift identities as easily as signing into a new login. Just as in the mind, desire can create a new BWO. A computer flicks on and it all becomes easier. Better.

It feels better at any rate.

But I do not believe it is good for me.

The time is Now. The Place is Here.

Things that can be taken with you, put in your pocket!

The digital technology of expanded cinema which has the ability to manipulate capture reform change images, has progressed to a point where the idea of an image, the video, a piece of art, it is no longer static. In this digital world it, too, becomes a living thing growing and changing. The very nature of this new digital technology is liquid. Take for example Danger Mouse's Grey Album. Two well-established musical art pieces, the White Album, and the Black Album by the Beatles and Jay-Z respectively. Images taken off the web manipulated and changed to create a new thing. The Grey Album. Two seemingly static pieces of art taken by an artist, Danger Mouse, and transformed, evolved, grown into something new. Steve F Anderson theorizes on the effects of the Grey Album on the art community, and how the open - liquid - world of youtube allows artists to change the location of the art studio to the computer screen, and the gallery space to the internet.

Taken in aggregate, however, I believe the downhill Battle protest, coupled with the widespread, illicit circulation of the Grey Video may be seen as exemplary of a mode of practice that is defined by the logic of the open-source network at the level of production, distribution, and reception. 53

Living and breathing on the internet.

Some artists work exclusively with content found on the Internet.

The liquidity or malleability, the instantaneous ability to change has of course been used for other purposes other than art. Take for example the 2011 "Arab Spring". Images

53 Anderson, Steve F. "Aporias of the Digital Avant-Garde “ in Digital Humanities Quarterly : Summer 2007 Volume 1. Number 2. Pg. 12. 
recorded and released to the web of violence. One moment one side claims that the images are proof of a brutal regime, that they were the ones being attacked, and then the next moment the images would be claimed as proof for the deception and of the rebels, both sides using the same moving images as unquestionable evidence of their argument. The very nature of the images changes by editing and juxtapositioning. Images that spread around the world. Icons were formed. Governments toppled. And ideologies upheld. This is the power of the liquid nature of digital technology.

One can take an image or video from the web and change it into bloody rebellion or pop art.

The "moment of no return" has shifted to POST production. Some artists now work in that realm, exclusively. Not filming anything. Just taking, editing, manipulating and distributing back out onto the web for consumption. So is youtube the new art gallery space??? The "Moment of creation" in filmmaking is shifting from the opening of the shutter to the clicking of a keyboard. The space for consumption is also shifting. Digital production has lent a flexibility to the installation art...

Easier to appropriate the image DOWNLOAD it scan it manipulate it..

The installation space is changing.

Yes.

People are now existing purely on the internet. Artists are existing purely on the internet. Art is existing purely on the internet.

Yes. 


\section{You Tube $_{\text {is }}{ }_{\text {is a callery. }}$}

So is your computer.

So is your phone.

So is your mind.

Digital installation art is water.

It's a pool to drink from.
Amy Audubon? ?
Changing Identity
I am A woman...

With a click She downloaded my Work MY VIDEO.

She made her own...

That is the ARTIST.

The Surfacing Woman. BECOMING 
In the first chapter I was many personas, all of them electronic. What could be more of a cyborg than the joining of bits of data and fingers on the keyboard to create a new person? From this state I declare my womanhood. I cemented it in reality, my body has taken shape. I have shifted. I am becoming.

I am a woman.

Drowning in all those things that we drown in but so much more.

WHAT DO WOMEN DROWN IN???

Drowning in Artistic Doubt?

Playing with space?

Turning a Man's work into my own.

Dealing with Intimacy.

Transforming into a woman.

To be sure it is not a Gender Fluidity, but a specific change of forms, a transience. A state of becoming. The search for a new identity.

I am The Surfacing Woman, this is my Gallery. This is my space. This is my body.

In my space I ask you to release your body and travel into the virtual world.

Where do you feel the most intimacy ???

In this space with art work you helped me create. I think with your words... sharing it with others??

On the web.... This is the PLACE you entered the piece.

In the false city hidden from everyone else with your head buried in a tank, experiencing the video by yourself.

What is the installation piece??

Is just a movie?

Is it more?

Is it less? 
Do you remember us?

We are the drowning.

Do you remember us?

We Are Drowning.

I am Drowning.

I rise back to the surface.

I become

\section{The}

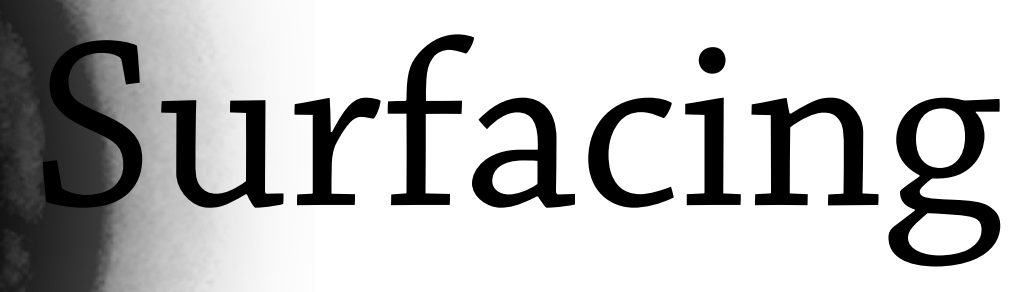

Woman

I am becoming. 
THE FOLLOWING

\section{WILL BE HANDWRITTEN}

Back to the start.

I am the swimming man.

I am surfacing woman.

I am the author.

I am the writer.

I am the scholar.

I am only me.

So now that we are at the end of this thing called my education what does this research tell us?

The ever changing and modifying technology of expanded cinema has profound effects on the way artists create, think, and even live. Zygmut Baumans' theory of liquid modernity emphasizes a rapid and ever-changing society, we can see how this parallels with digital technology. Both society and technology feeding into one another creating a synergistic loop of even more rapid change.

So this liquid society and this liquid technology allows and simultaneously challenges artists and filmmakers to constantly come up with something new and fresh. At the same time they allow these artists and filmmakers to express every whim at a moments notice. They also allow the art in the film to be broadcast anywhere throwing away constraints and allowing or forcing the artist to confront the constraints within him or herself.

\section{Bringing it back to the start.}




\section{Bibliography}

Anderson, Steve F. "Aporias of the Digital Avant-Garde " in Digital Humanities Quarterly: Summer 2007 Volume 1. Number 2.

Austerlitz, Saul. Money for Nothing : A History of the Music Video, from the Beatles to the White Stripes. New York: Continuum, 2007.

Bauman, Zygmunt. Liquid Modernity. Cambridge Malden, MA: Polity Press ; Blackwell, 2000.

Bauman, Zygmunt. Liquid Love : On the Frailty of Human Bonds. Cambridge, UK Malden, MA: Polity Press ; Distributed in the USA by Blackwell Pub., 2003.

Bauman, Zygmunt. Liquid Life. Cambridge Malden, MA: Polity Press ; Blackwell, 2005.

Bauman, Zygmunt. Liquid Times : Living in an Age of Uncertainty. 1 p. Cambridge: Polity Press, 2007.

Beebe, Roger, and Jason Middleton. Medium Cool : Music Videos from Soundies to Cellphones. Durham, N.C.: Duke University Press, 2007.

Deleuze, Gilles, and Félix Guattari. A Thousand Plateaus : Capitalism and Schizophrenia. London: Athlone Press, 1988.

Export, Valie. (5 October 2003). Expanded Cinema as Expanded Reality, Accessed on August 15 2011. at http://www.sensesofcinema.com/2003/28/expanded_cinema/.

Fancy, David. Difference, bodies, desire: The collaborative thought of Gilles Deleuze and Félix Guattari in Science Fiction Film and Television - Volume 3, Issue 1, Spring 2010.

Gaggi, Silvio. From Text to Hypertext : Decentering the Subject in Fiction, Film, the Visual Arts, and Electronic Media, Penn Studies in Contemporary American Fiction. Philadelphia, Pa.: University of Pennsylvania Press, 1997.

Hanson, Matt. Reinventing Music Video : Next-Generation Directors, Their Inspiration, and Work. Amsterdam ; Boston: Focal Press, 2006.

Joe, Grant. "Fantasia." In American Film Institute Catalog. United States: Walt Disney Productions, 1942.

Kinder, Marsha. "Music Video and the Spectator: Television, Ideology and Dream." Film Quarterly 38, no. 1 (1984): 2-15.

Lovecraft, H. P., August William Derleth, and S. T. Joshi. Dagon and Other Macabre Tales. Corr. 5th print. ed. Sauk City, Wis.: Arkham House Publishers, 1987.

Miller, Toby, and Robert Stam. Film and Theory : An Anthology. Malden, Mass.: Blackwell Publishers, 2000.

Mulvey, Laura. "Stillness in the Moving Image: Ways of Visualizing Time and Its Passing" in Saving the Image: Art After Film. Eds. Tanya Leighton \& Pavel Büchler. Glasgow: Centre for Contemporary Arts, 2003.

Pasolini, Pier Paolo, "Observations on the Long Take" in The Cinematic: Documents of Contemporary Art. Ed David Campany. London

Cambridge, Mass.: Whitechapel ; MIT Press, 2007.

Shuker, Roy. Popular Music : The Key Concepts, Routledge Key Guides. London: Routledge, 2002.

Sobchek, Vivian. (4 April 2000). What My Fingers Knew: The Cinesthetic Subject, or Vision in the Flesh, Accessed June 202011 at http://archive.sensesofcinema.com/contents/00/5/fingers.html. 
Sobchack, Vivian, 'Cities on the Edge of Time: The Urban Science Fiction Film', in Sean Redmond Ed. Liquid Metal: The Science Fiction Film Reader, London: Wallflower. (2004) p.78.

Vernallis, Carol. Experiencing Music Video : Aesthetics and Cultural Context. New York: Columbia University Press, 2004.

Willis, Holly. New Digital Cinema : Reinventing the Moving Image, Short Cuts Series. London: Wallflower Press, 2005.

Wood, Aylish. Digital Encounters. London ; New York: Routledge, 2007. 